NASA/TM-2004-213079

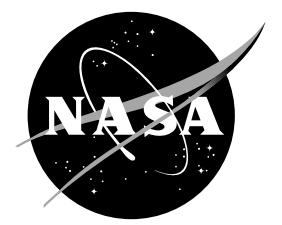

\title{
Predictions for the Effects of Free Stream Turbulence on Turbine Blade Heat Transfer
}

Robert J. Boyle

Glenn Research Center, Cleveland, Ohio

Paul W. Giel

QSS Group, Inc., Cleveland, Ohio

Forrest E. Ames

University of North Dakota, Grand Forks, North Dakota 
Since its founding, NASA has been dedicated to the advancement of aeronautics and space science. The NASA Scientific and Technical Information (STI) Program Office plays a key part in helping NASA maintain this important role.

The NASA STI Program Office is operated by Langley Research Center, the Lead Center for NASA's scientific and technical information. The NASA STI Program Office provides access to the NASA STI Database, the largest collection of aeronautical and space science STI in the world. The Program Office is also NASA's institutional mechanism for disseminating the results of its research and development activities. These results are published by NASA in the NASA STI Report Series, which includes the following report types:

- $\quad$ TECHNICAL PUBLICATION. Reports of completed research or a major significant phase of research that present the results of NASA programs and include extensive data or theoretical analysis. Includes compilations of significant scientific and technical data and information deemed to be of continuing reference value. NASA's counterpart of peerreviewed formal professional papers but has less stringent limitations on manuscript length and extent of graphic presentations.

- TECHNICAL MEMORANDUM. Scientific and technical findings that are preliminary or of specialized interest, e.g., quick release reports, working papers, and bibliographies that contain minimal annotation. Does not contain extensive analysis.

- CONTRACTOR REPORT. Scientific and technical findings by NASA-sponsored contractors and grantees.
- CONFERENCE PUBLICATION. Collected papers from scientific and technical conferences, symposia, seminars, or other meetings sponsored or cosponsored by NASA.

- SPECIAL PUBLICATION. Scientific, technical, or historical information from NASA programs, projects, and missions, often concerned with subjects having substantial public interest.

- TECHNICAL TRANSLATION. Englishlanguage translations of foreign scientific and technical material pertinent to NASA's mission.

Specialized services that complement the STI Program Office's diverse offerings include creating custom thesauri, building customized databases, organizing and publishing research results ... even providing videos.

For more information about the NASA STI Program Office, see the following:

- Access the NASA STI Program Home Page at http://www.sti.nasa.gov

- E-mail your question via the Internet to help@sti.nasa.gov

- Fax your question to the NASA Access Help Desk at 301-621-0134

- Telephone the NASA Access Help Desk at 301-621-0390

- Write to:

NASA Access Help Desk

NASA Center for AeroSpace Information 7121 Standard Drive

Hanover, MD 21076 
NASA/TM-2004-213079

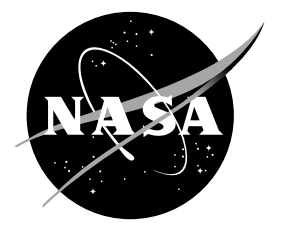

\section{Predictions for the Effects of Free Stream Turbulence on Turbine Blade Heat Transfer}

Robert J. Boyle

Glenn Research Center, Cleveland, Ohio

Paul W. Giel

QSS Group, Inc., Cleveland, Ohio

Forrest E. Ames

University of North Dakota, Grand Forks, North Dakota

Prepared for the

Turbo Expo 2004

sponsored by the American Society of Mechanical Engineers

Vienna, Austria, June 14-17, 2004

National Aeronautics and

Space Administration

Glenn Research Center 


\section{Acknowledgments}

We would like to express our appreciation to Dr. Tony Arts, Dr. Je-Chin Han, and Dr. Karen Thole for providing the data used in the comparisons.

Available from

NASA Center for Aerospace Information 7121 Standard Drive

Hanover, MD 21076
National Technical Information Service 5285 Port Royal Road Springfield, VA 22100

Available electronically at http:/ /gltrs.grc.nasa.gov 


\title{
Predictions for the Effects of Free Stream Turbulence on Turbine Blade Heat Transfer
}

\author{
Robert J. Boyle \\ National Aeronautics and Space Administration \\ Glenn Research Center \\ Cleveland, Ohio 44135 \\ Paul W. Giel \\ QSS Group, Inc. \\ Cleveland, Ohio 44135 \\ Forrest E. Ames \\ University of North Dakota \\ Grand Forks, North Dakota 58202
}

\begin{abstract}
An approach to predicting the effects of freestream turbulence on turbine vane and blade heat transfer is described. Four models for predicting the effects of freestream turbulence were incorporated into a NavierStokes CFD analysis. Predictions were compared with experimental data in order to identify an appropriate model for use across a wide range of flow conditions. The analyses were compared with data from five vane geometries and from four rotor geometries. Each of these nine geometries had data for different Reynolds numbers. Comparisons were made for twenty four cases. Steady state calculations were done because all experimental data were obtained in steady state tests. High turbulence levels often result in suction surface transition upstream of the throat, while at low to moderate Reynolds numbers the pressure surface remains laminar. A two-dimensional analysis was used because the flow is predominantly two-dimensional in the regions where freestream turbulence significantly augments surface heat transfer. Because the evaluation of models for predicting turbulence effects can be affected by other factors, the paper discusses modeling for transition, relaminarization, and near wall damping. Quantitative comparisons are given between the predictions and data.

\section{Nomenclature}

$\begin{array}{lll}A^{+} & - & \text {Near wall damping coefficient } \\ C & - & \text { True chord } \\ C \mathrm{X} & - \text { Axial chord } \\ D & - & \text { Leading edge diameter } \\ h & - & \text { heat transfer coefficient } \\ K & - & \text { Acceleration parameter, }\left(\nu / U^{2}\right)(d U / d s) \\ k & - & \text { Turbulent kinetic energy } \\ L & - & \text { Length scale } \\ M & - & \text { Mach number } \\ N u & - & \text { Nusselt number } \\ P^{+} & - \text {Pressure gradient parameter } \\ R e & - \text { True chord exit Reynolds number } \\ s & - \text { Surface distance }\end{array}$
\end{abstract}

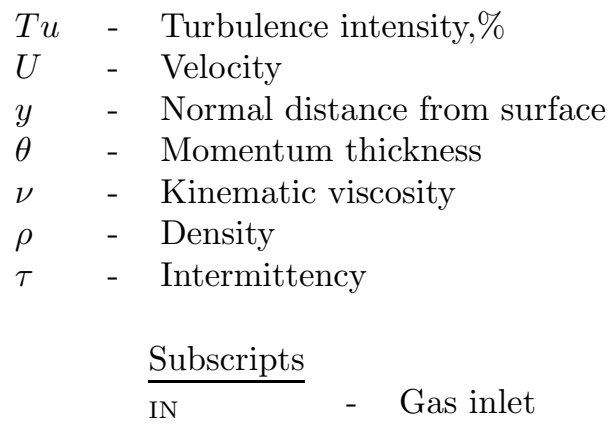

\section{INTRODUCTION}

Accurate predictive modeling of heat transfer on gas turbine vanes and blades is a key concern in engine design systems. The desirability of higher turbine entry temperatures and increased airfoil life are facilitated by accurate blade heat transfer modeling. Among the many physical phenomena which influence turbine blade heat transfer are freestream turbulence intensity and length scale. The effects of freestream turbulence on heat transfer have been examined experimentally by many researchers. Using flat plate measurements, Blair [1] correlated changes in Stanton number to levels of turbulence intensity, length scale, and Reynolds number. This work was extended to a large, low-speed stator/rotor rig by Blair [2]. The first stator showed strong effects of inlet $T u$. The rotor showed changes only near the leading edge due to changes in stator inlet turbulence. But, rotors experience high periodic turbulence due to wake passing. Krishnamoorthy and Sukhatme [3] made measurements and developed correlations that included the effects of freestream turbulence on a vane and a blade in a cascade. The correlations predicted a $75 \%$ increase in laminar heat transfer for a local turbulence intensity of twelve percent. The effects of turbulence scale were examined by Galassi et al. [4] on a rotor in a linear cascade. They showed that the Nusselt number increased as the scale of the turbulence decreased. Leading edge effects of freestream turbulence were examined by 
Mehendale et al. [5], who showed a peak augmentation of 44\%. Svensdotter and Fransson [6] measured heat transfer on a vane in a linear cascade and focussed on transition locations and the effects of inlet Tu. At a turbulence level of ten percent, less than a six fold increase in Reynolds number resulted in nearly a five fold increase in the minimum heat transfer rate. At a turbulence level of $5.5 \%$, the increase in minimum heat transfer rate was closer to the factor of 2.2 which would be expected for laminar flow.

Various approaches have been used to predict turbine blade heat transfer. Ames et al. [7] used the STAN7 boundary layer code of Kays [8] for heat transfer predictions. Boyle and Simon [9] incorporated empirical models for the effects of turbulence on transition into a two-dimensional Navier-Stokes CFD code to predict blade heat transfer. Because accurate transition predictions are needed for accurate heat transfer predictions, intermittency transport equations have been proposed. Vicedo et al. [10] proposed a model for predicting separated flow transition. Suzen et al. [11] proposed a model, and used it to predict the performance of low pressure turbines. Steelant and Dick [12] proposed a model for predicting by-pass transition using conditionally averaged Navier-Stokes equations. The intermittency transport modeling approaches have been verified using aerodynamic data, but have not been extensively used for heat transfer predictions.

The present work examines approaches to predicting the effects of freestream turbulence intensity and scale on turbine blade heat heat transfer. Freestream turbulence primarily increases laminar heat transfer and promotes early transition. If transition occurs close to the leading edge, and a strong enough favorable pressure gradient follows, the surface flow is seen experimentally to relaminarize. Modeling of this phenomena is incorporated in the present investigation. The work seeks to identify an approach to predicting heat transfer which is reasonably accurate when comparisons are made with experimental data from a large variety of sources. In addition to graphical comparisons, quantitative average heat transfer comparisons are made. Comparisons are made with heat transfer data for nine turbine vane and rotor geometries for a total of twenty four cases. The data cover a wide range of Reynolds and Mach numbers, turbulence intensities, and length scales. The focus of this work is on the effects of turbulence. Therefore, only the high turbulence intensity cases will be discussed.

A two-dimensional steady state CFD analysis was used to compare predictions with data for nine different blade geometries, each for a range of flow conditions. The appropriate modeling approaches can be implemented in threedimensional steady and unsteady analyses to predict turbine blade heat transfer in an engine environment.

\section{DESCRIPTION of ANALYSIS}

The two primary issues explored in this paper are different models for the effects of freestream turbulence and modeling of the variation of freestream turbulence intensity. The relaminarization criteria is also discussed.

Effects of freestream turbulence on heat transfer. The early work for the effects of freestream turbulence focused on the leading edge region. Smith and Kuethe [13] gave a model for the viscosity due to freestream turbulence, $\nu_{\mathrm{Tu}}$, as:

$$
\nu_{\mathrm{Tu}}=C_{\mathrm{SK}} T u U y
$$

where $C_{\mathrm{SK}}=0.00164$. In the model $\nu_{\mathrm{Tu}}$ is added to the laminar viscosity, $\nu_{\mathrm{LAM}}$. This model, labeled as the SK model, accounts for turbulence intensity, but does not account for the scale of turbulence.

Van Fossen et al.[14] measured the augmentation due to freestream turbulence as a function of the scale of turbulence. Data were obtained for isolated cylindrical and elliptical leading edges. These data were correlated and showed that the augmentation varied as $L^{-1 / 3}$. The $-1 / 3$ exponent was also used by Dullenkopf and Mayle [15]. Boyle et al. [16] used the data of Van Fossen et al. [14] to modify the Smith and Kuethe correlation in order to account for the scale of turbulence. The resulting equation for isotropic turbulence is:

$$
\nu_{\mathrm{Tu}}=C_{\mathrm{VF}} C_{\mathrm{SK}} T u U y(D / L)^{1 / 3}
$$

where $C_{\mathrm{VF}}=0.3$. This model is designated as the SKVF model. A small portion of the data in reference [14] was for non-isotropic turbulence. Reference 16 showed that for non-isotropic turbulence a value for $C_{\mathrm{VF}}$ near one was more appropriate.

Ames et al. [7] proposed two models for $\nu_{\mathrm{Tu}}$. The first is:

$$
\nu_{\mathrm{Tu}}=0.135 T u U L(1-\exp (-2.9 y / L))^{4 / 3} D_{\nu}
$$

where:

$$
D_{\nu}=1-\exp \left(\frac{-0.15 y}{\left(L \nu^{3} / 1.5\left|u^{\prime}\right|^{3}\right)^{1 / 4}}\right)
$$

$u^{\prime}$ is found from $u^{\prime}=0.01 T u U$. This model is designated the AMS model

The second model incorporates a leading edge effect to give:

$$
\nu_{\mathrm{Tu}}^{*} / \nu_{\mathrm{Tu}}=1+\left(\left(R e_{\mathrm{D}} / 4\right)^{1 / 12}-1\right) f_{\mathrm{amp}}
$$


$\nu_{\mathrm{Tu}}$ is calculated as in the AMS model, and $\nu_{\mathrm{Tu}}^{*}$ is the complete model. The term $f_{\text {amp }}$ is used to cause $\nu_{\text {Tu }}^{*}$ to become $\nu_{\mathrm{Tu}}$ away from the leading edge. It is given by:

$$
f_{\mathrm{amp}}=1.0-\exp \left(-2.5\left(\frac{d U(s) / d s}{d U(s=0) / d s}\right)^{2}\right)
$$

Since this model is intended to apply in the leading edge region, $f_{\text {amp }}$ was set to zero once $d U / d s<0$. This model is designated the AMLE model.

The SK, SKVF, and AMLE models were developed to account for augmentation in leading edge region. An objective of this work is to determine how well these models predict heat transfer away from the leading edge region.

Figure 1 shows the variation of $\nu_{\mathrm{Tu}} / \nu_{\mathrm{LAM}}$ with distance from the blade surface for typical conditions. Near the wall both the AMS and ALE models have much lower values than either the SK or SKVF models, and the figure shows that these lower values are due to the damping term. If heat transfer augmentation is primarily determined by near wall augmentation, the undamped models, (SK and SKVF), are expected to show significantly higher augmentation than the AMS or AMLE models. However, if augmentation in the outer region of the boundary layer is significant, then the differences among the four models may be small. Since $L / D=1.0$ is constant, the SKVF model values are $30 \%$ of the SK model values.

The SK and SKVF models use an integral length scale, while the AMS and AMLE models use an energy length scale. In the comparisons the same length scale was used for all models. Measurements given by Ames [17] showed a variable ratio for the two length scales, but the integral length scale was at least half of the energy length scale.

Transition modeling. An accurate evaluation of any model for the effects of freestream turbulence requires accurate models for the start and length of transition. The start of transition was predicted using Mayle's [18] model.

$$
\left(R e_{\theta}\right)_{\mathrm{START}}=400 T u^{-5 / 8}
$$

The local value of $R e_{\theta}$ was determined using Twaites's approach as given by White [19]. The calculation of the local value of $T u$ was done using two approaches. In one approach $u^{\prime}$ was assumed constant, so that $T u U$ remains constant. Consequently, around the blade $T u U$ is equal to its upstream value. Calculations made using this assumption are denoted as the constant $k$ predictions.

The second approach uses the model of Steelant and Dick [20], where:

$$
T u=T u_{\mathrm{IN}}\left(U_{\mathrm{IN}} / U\right)^{3 / 2}
$$

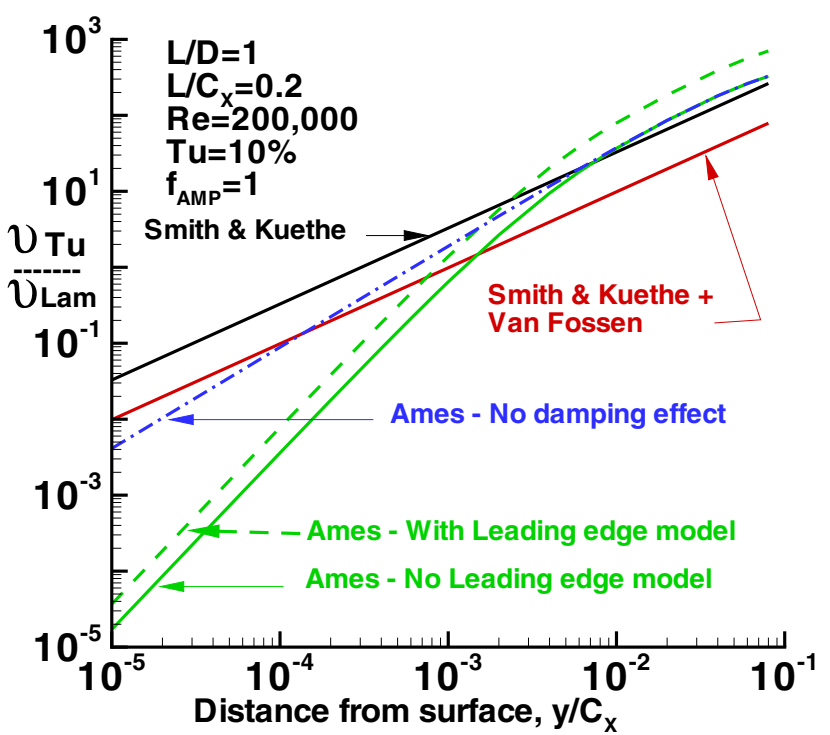

Fig. 1 Viscosity ratio variation with distance

Here, the $T u U$ product does not remain constant. When the inviscid velocity is twice the inlet velocity, the local freestream turbulence is only $35 \%$ of the inlet value. Measurements of the turbulence intensity at the inlet and exit of a vane cascade by Boyle et al. [21], and by Zhang and Han [22] for a rotor cascade showed a decrease in $T u$ consistent with the Steelant and Dick model. Calculations made with this assumption are denoted as the SD predictions.

No attempt was made to account for the effects of the scale of turbulence on the start or length of transition. Jonas et al. [23] showed that the start and length were affected by the scale of turbulence. However, in their experiments both the turbulence intensity and scale varied simultaneously. Using Mayle's model to recalculate the experimental start of transition to a common turbulence intensity showed no significant effects of the scale of turbulence on either the start or length of transition.

The transition length was calculated using the procedure described by Boyle and Simon [9], which applies a Mach number correction to the transition length model described by Solomon et al. [24]. Predictions using this model are labeled SWGM. Predictions were also made using the Abu-Ghannam and Shaw [25] transition length model. Predictions using this model are labeled AGS.

Relaminarization. Heat transfer distributions consistent with relaminarized flow were often seen on rotor pressure surfaces. Relaminarization was assumed to occur whenever $K$ exceeded a critical value of $3 \times 10^{-6}$. $K$ was calculated either from the local velocity gradient, or from the lagged value of the pressure gradient parameter, $P^{+}$.

$$
K=-P^{+}\left(C_{\mathrm{f}} / 2\right)^{3 / 2}
$$


Table I. Description of test cases.

\begin{tabular}{|c|c|c|c|c|c|c|}
\hline $\begin{array}{r}\text { Source } \\
\text { Ref. }\end{array}$ & $\begin{array}{c}R e_{2} \\
\times 10^{-6}\end{array}$ & $\begin{array}{r}T u_{\mathrm{IN}} \\
\%\end{array}$ & $L / C_{\mathrm{X}}$ & $D_{\mathrm{LE}} / C_{\mathrm{X}}$ & $M_{2}$ & $C_{\mathrm{x}} / C$ \\
\hline \multicolumn{7}{|c|}{ Vanes } \\
\hline \multirow[t]{2}{*}{7} & 0.50 & 13.1 & 0.29 & 0.22 & 0.05 & 0.52 \\
\hline & 2.00 & 13.4 & 0.29 & & 0.19 & \\
\hline \multirow[t]{2}{*}{30} & 0.50 & 20.9 & 0.24 & 0.21 & 0.05 & 0.54 \\
\hline & 2.00 & 20.3 & 0.28 & & 0.18 & \\
\hline \multirow[t]{2}{*}{17} & 0.52 & 12.4 & 0.40 & 0.30 & 0.27 & 0.54 \\
\hline & 0.80 & 12.0 & 0.43 & & 0.27 & \\
\hline \multirow[t]{2}{*}{31} & 1.11 & 10.0 & 0.41 & 0.61 & 0.08 & 0.49 \\
\hline & 1.11 & 19.5 & 0.41 & & 0.08 & \\
\hline \multirow[t]{4}{*}{32} & 0.55 & 6.0 & 0.18 & 0.22 & 1.1 & 0.55 \\
\hline & 1.09 & 6.0 & 0.18 & & 1.1 & \\
\hline & 2.11 & 6.0 & 0.18 & & 0.92 & \\
\hline & 2.11 & 6.0 & 0.18 & & 1.1 & \\
\hline \multicolumn{7}{|c|}{ Rotors } \\
\hline \multirow[t]{2}{*}{22} & 0.30 & 14 & 0.01 & 0.10 & 0.05 & 0.75 \\
\hline & 0.91 & 17 & 0.01 & & 0.14 & \\
\hline \multirow[t]{2}{*}{33} & 0.73 & 13 & 0.42 & 0.08 & 0.79 & 0.86 \\
\hline & 1.03 & 13 & 0.42 & & 0.69 & \\
\hline \multirow[t]{3}{*}{34} & 0.45 & 13 & 0.45 & 0.14 & 0.75 & 0.83 \\
\hline & 0.75 & 13 & 0.45 & & 0.75 & \\
\hline & 1.49 & 13 & 0.45 & & 0.74 & \\
\hline \multirow[t]{5}{*}{35} & 0.54 & 4 & 0.11 & 0.10 & 1.05 & 0.88 \\
\hline & 1.05 & 6 & 0.11 & & 1.05 & \\
\hline & 1.05 & 4 & 0.11 & & 0.8 & \\
\hline & 1.05 & 4 & 0.11 & & 1.3 & \\
\hline & 1.84 & 4 & 0.11 & & 1.05 & \\
\hline
\end{tabular}

where $C_{\mathrm{f}} / 2$ is the friction coefficient. Lagging was done using the approach described by Crawford and Kays [26].

When the intermittency, $\tau$, was $>0$, and the flow was no longer laminar, the turbulent eddy viscosity, $\nu_{\mathrm{t}}$, was calculated using the algebraic turbulence model described by Chima et al. [27]. The effect of assuming the near wall damping coefficient in the turbulence model, $A^{+}$, to be a function of $P^{+}$was also examined.

Since correlations were used for the start and length of transition as well as specifying relaminarization, it was felt that an algebraic turbulence model was appropriate. Many of the cases examined were in the transitional flow regime. Two-equation models, such as the one described by Ameri and Arnone [28], tend to mimic transition, but do not accurately predict it.

In summary, the total viscosity is given by:

$$
\nu_{\mathrm{TOTAL}}=\nu_{\mathrm{LAM}}+(1-\tau) \nu_{\mathrm{Tu}}+\tau \nu_{\mathrm{t}}
$$

These models were implemented in the quasi-3D Navier-Stokes code RVCQ3D. This code has been documented by Chima [29]. All of the test cases were linear cascades, so that only a two-dimensional analysis was done. C-type grids, typically $377 \times 55$, were used. Reference 9 gives a more detailed description of the analysis. The solutions were monitored to assure that convergence was achieved.
Table II. Designation for model assumptions

\begin{tabular}{|l|c|l|l|l|}
\hline Aug. & $\begin{array}{c}\text { Tu } \\
\text { variation }\end{array}$ & Relamin. & $\begin{array}{l}\text { Transition } \\
\text { length }\end{array}$ & $\begin{array}{l}\text { Near wall } \\
\text { damping }\end{array}$ \\
\hline None & SD & Lagged & SWGM & Var $A^{+}$ \\
SKVF & SD & Lagged & SWGM & Var $A^{+}$ \\
AMS & SD & Lagged & SWGM & Var $A^{+}$ \\
AMLE & SD & Lagged & SWGM & Var $A^{+}$ \\
AMS & constant $k$ & Lagged & SWGM & Var $A^{+}$ \\
AMS & SD & Yes & SWGM & Var $A^{+}$ \\
AMS & SD & No & SWGM & Var $A^{+}$ \\
AMS & SD & Lagged & AGS & Var $A^{+}$ \\
AMS & SD & Lagged & SWGM & $A^{+}=26$ \\
\hline
\end{tabular}

\section{DISCUSSION of RESULTS}

Comparisons were made with nine different blade geometries. Five were vane geometries and four were rotor geometries. Table 1 gives some of the characteristics of the cases examined. The vane cases of Ames et al. [7] were for a large scale vane at low Mach numbers. The cases of Ames et al. [30] were for a different geometry, which produced a more aft loaded vane. The cases of Ames [17] were a third geometry, and was tested at an exit Mach number of 0.27. The vane of Radomsky and Thole [31] had a distinctive geometry, which resulted in a forward loaded vane. Ideally, all cases would have both the inlet turbulence intensity and length scale specified. However, most of the vane test cases that met this requirement were for incompressible exit Mach numbers. The vane cases of Arts et al. [32] were included even though the length scale could only be estimated because the data were at engine typical Mach numbers.

Only the rotor of Zhang and Han [22] was for an incompressible exit Mach number. The rotors of Giel et al. [33], and that of Giel et al. [34] were tested in the same facility, but the blade geometries and Reynolds numbers were different. The rotor cases of Arts et al. [35] was included even though the length scale could only be estimated, because it had both a different geometry and an engine realistic wall-to-gas temperature ratio.

Table II shows the the model assumptions used for the comparisons with data. The labels shown in Table II are also used later in Table III, where quantitative summaries are given for the ten modeling assumptions. The first five entries in Table II are for different augmentation models, and a common set of other modeling assumptions. The next five entries use the AMS augmentation model and vary one other model assumption. The variable $A^{+}$calculations were done using the relationship given by Crawford and Kays [26] for $A^{+}$as a function of $P^{+}$. Calculations were also done using the relationship of Cebeci and Smith [36] for $A^{+}$as a function of $P^{+}$. They are not discussed, since the results were close to those assuming $A^{+}=26$. 


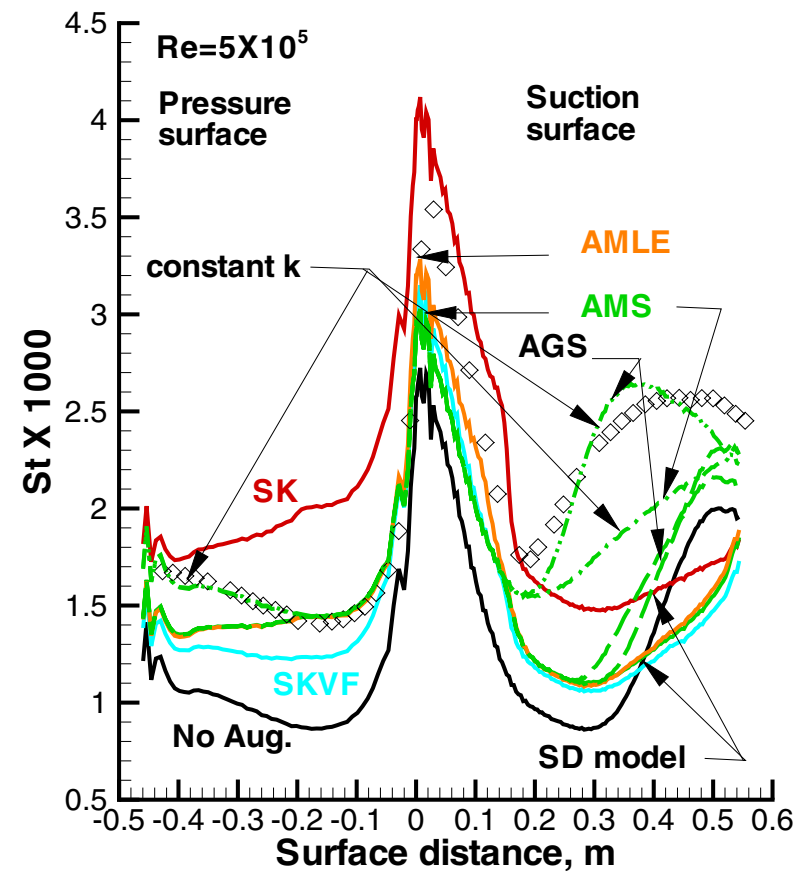

a) $\mathrm{Re}=500,000$

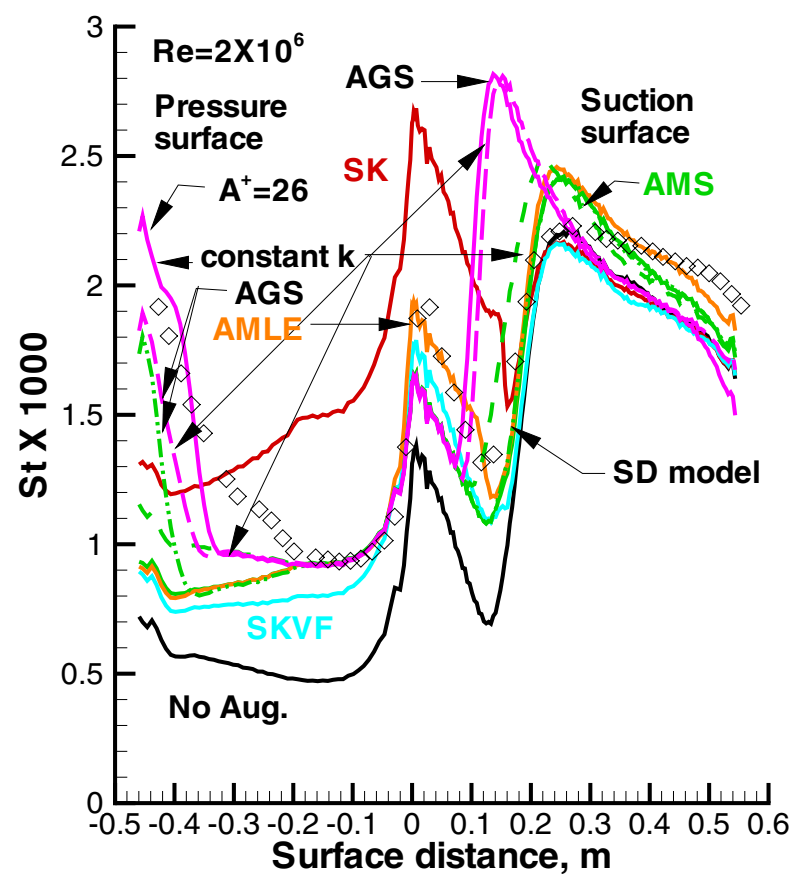

a) $\mathrm{Re}=2,000,000$

Fig. 2 Comparisons with data of Ames et al.[7]

Other combinations of model assumptions were examined, and will be mentioned. Overall, the other combinations did not yield better agreement with data. In the following figures the prediction curves are color coded to denote the augmentation model used. Lines with no augmentation are black. Lines using the SK model are red, and those using the SKVF model are cyan. The AMS model results are in green, and the AMLE model results are in orange. When purple is used, the AMS model assumption was always made.

For discussion purposes the blade surface is divided into three regions: pressure surface, leading edge region, and suction surface. The leading edge region begins near the minimum heat transfer point on the pressure surface, and extends to the first minimum on the suction surface.

This work focuses on heat transfer comparisons for high inlet turbulence intensities. While comparisons were done for both surface pressure distributions and low turbulence intensity heat transfer cases, they are not included. Differences between measured and predicted pressure distributions were not large, and were not believed to be the cause of disagreements between calculations and data. At low inlet $T u$, measurements generally showed laminar heat transfer distributions, and the analysis accurately predicted theses cases.

\section{Vanes}

Ames et al. [7]. Figure 2 shows comparisons for two Reynolds numbers for the cases given in reference 7 . The comparisons at $R e=0.5 \times 10^{6}$ show excellent agreement with the pressure surface heat transfer using the AMS model with the constant $k$ assumption for the variation in freestream turbulence. The AMLE model results for the pressure surface away from the leading edge were the same as those for the AMS model. Accounting for turbulence effects using these models increases the pressure side heat transfer by nearly $50 \%$. No augmentation underpredicts the data everywhere, while the SK model overpredicts the heat transfer by nearly $50 \%$. The SKVF model results are somewhat lower than the AMS model results. For the rear half of the pressure surface the AMS and AMLE models have the same prediicted heat transfer. Here the SD assumption for the variation of freestream $T u$ underpredicts heat transfer. At the higher Reynolds number transition is seen earlier than predicted. The constant $\mathrm{k}$ assumption was somewhat better that the SD model, and AGS model agreed better with the data than the SWGM model. A further improvement is achieved when $A^{+}$is constant.

In the leading edge region the augmentation models use the inlet values for the $T u U$ product. In this region the SK model overpredicts the heat transfer. Although the AMLE model underpredicts the heat transfer, it is closer to the data than the other model predictions.

On the suction surface the AMLE model gives good agreement with data at the higher Reynolds number. Because of transition issues the agreement is not good at 


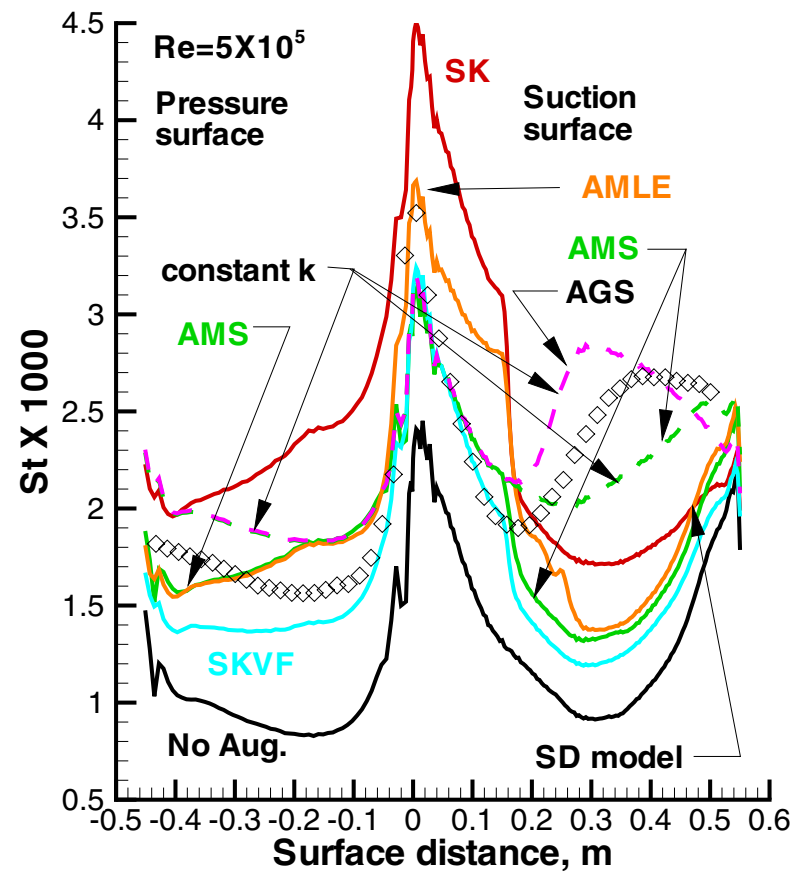

a) $\mathrm{Re}=500,000$

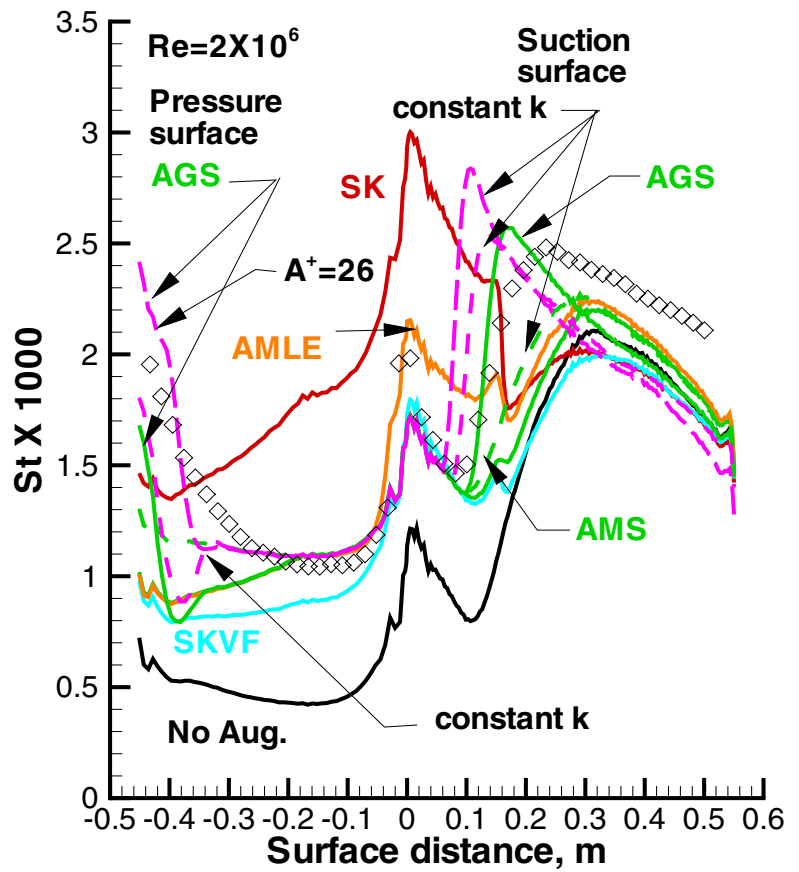

a) $\mathrm{Re}=2,000,000$

Fig. 3 Comparisons with data of Ames et al.[30]

the lower Reynolds number. The constant $k$ model for the variation of $T u$ significantly improves the agreement with data. The AGS transition length model in conjunction with the constant $k$ assumption is in very good agreement with data at the low Reynolds number. However, at the high Reynolds number these assumptions result in transition that is too early and too abrupt.

For this geometry the best agreement with data was achieved using the AMLE model and the AGS transition length model.

Ames et al.[30]. Figure 3 shows comparisons with the data from reference 30. While exit Mach and Reynolds numbers are the same as for the previous geometry, the vane pressure distribution differs, and the turbulence level is nearly $50 \%$ higher. Although the data in figures 2 and 3 are similar, the degree of agreement for each model assumption is different. The AMLE model results are in best agreement near the stagnation point. However, for the leading edge region as a whole, the AMS model is preferred for the comparisons in figure 3 . On the pressure surface the primary difference is that the constant $k$ assumption overpredicts the low Reynolds number data in figure 3. The AMS and AMLE models gave the best agreement for pressure side heat transfer. The AGS model is preferred over the SWGM model for the higher Reynolds number case. When used with the constant $k$ assumption and $A^{+}=26$ the pressure surface is again well predicted.

At the lower Reynolds number the suction surface heat transfer is not well predicted. The constant $k$ assumption for $T u$ variation is better. While the AGS transition length model is conservative, it is not closer to the data than the SWGM model. However, at the higher Reynolds number the SD model for $T u$ variation in conjunction with the AGS transition length model agrees well with the data in the transition region. Afterwards, the predictions fall off more rapidly than the data.

For this geometry the AMS model gives the best agreement with data. The AGS model for transition length is more appropriate for the pressure surface, but predicts too rapid a rise for the suction surface heat transfer. For the lower Reynolds number, assuming constant $k$ is appropriate. However, for the higher Reynolds number, the $\mathrm{SD}$ variation is better. The constant $k$ assumption gives gives higher heat transfer, and therefore a more conservative prediction. The results in figures 2 and 3 suggest that predictions be run using the constant $k$ assumption for $T u$ variation and the AGS transition length model.

Ames et al.[17]. The heat transfer results for the third vane are presented in figure 4 . The highest turbulence intensity was near $12 \%$, and data were obtained at Reynolds numbers of 0.52 and $0.8 \times 10^{6}$. The first thing to note is that in figure 4 the AGS transition length model gives poor agreement with the suction surface data. For the entire leading edge region the AMLE model gives good agreement with the experimental data. In this region the AMS model predicts slightly lower heat transfer. 


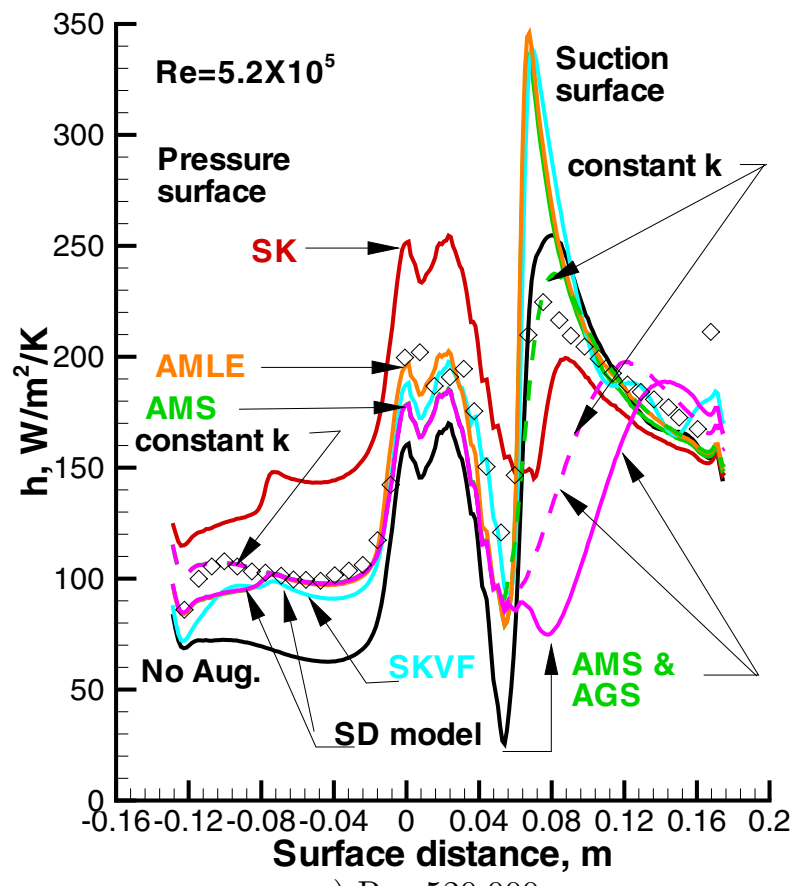

a) $\operatorname{Re}=520,000$

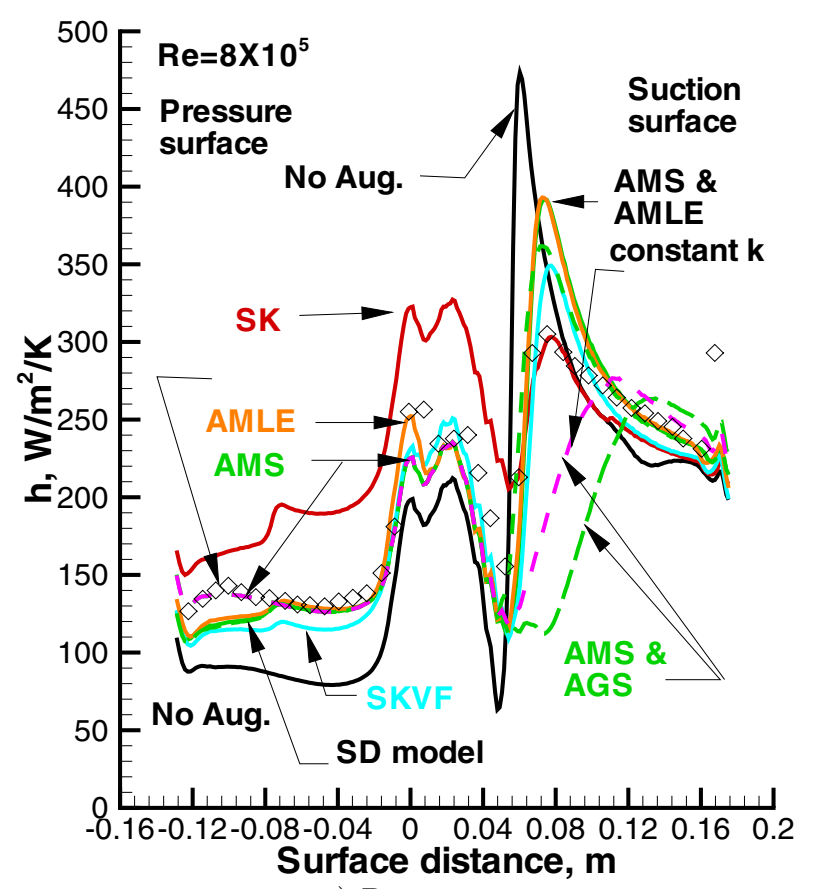

a) $\mathrm{Re}=800,000$

Fig. 4 Comparisons with data of Ames[17]

On the pressure surface the constant $k$ assumption agrees well with the data for either the AMS or AMLE model. The SKVF results are lower, but still significantly better than no augmentation. The SK model results are much higher than the data, everywhere, except after suction surface transition.

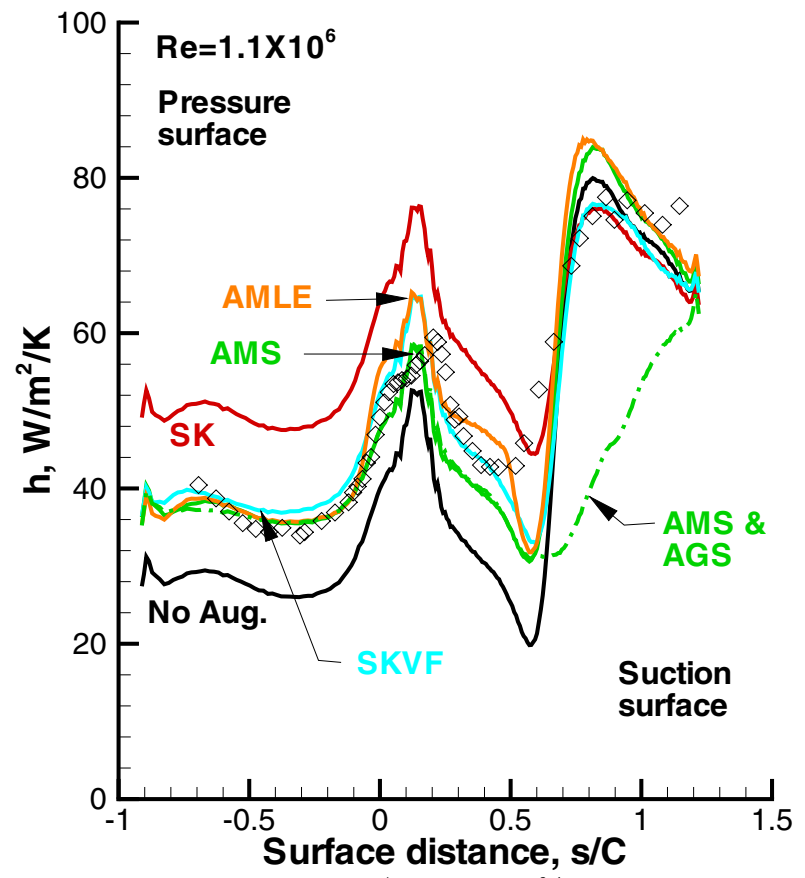

a) $T u=10 \%$

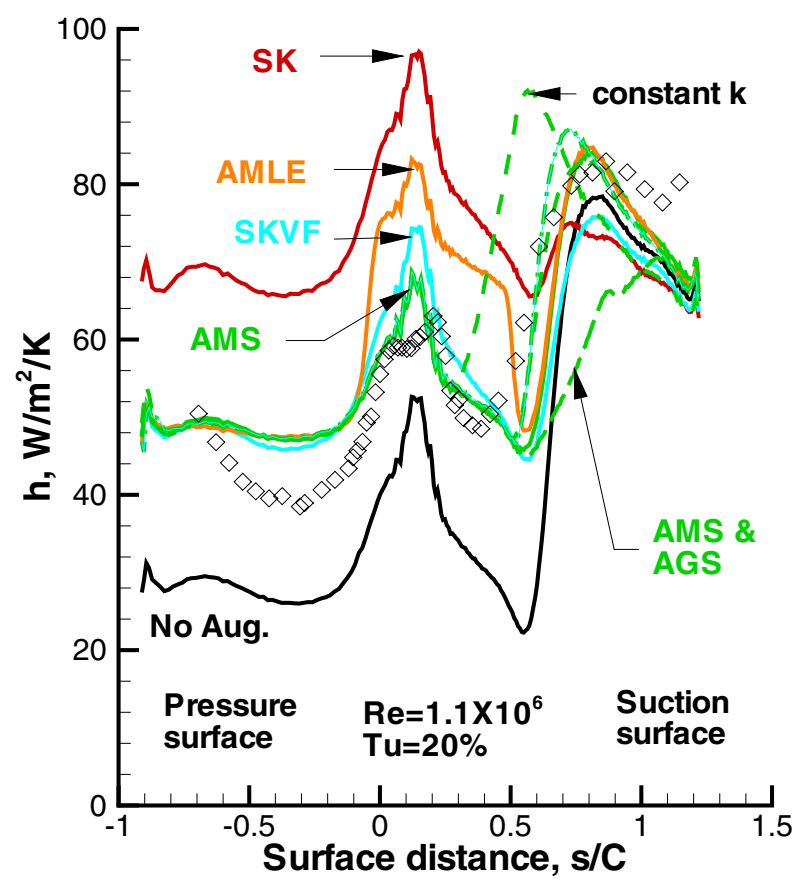

b) $T u=20 \%$

Fig. 5 Comparisons with data of Radomsky and Thole[31]

On the suction surface the transition location is well predicted using either the constant $k$ or SD assumptions for the variation in $T u$. Transition is rapid, and all models except the SK model excessively overpredict the heat transfer. This overprediction has only a small effect on the 


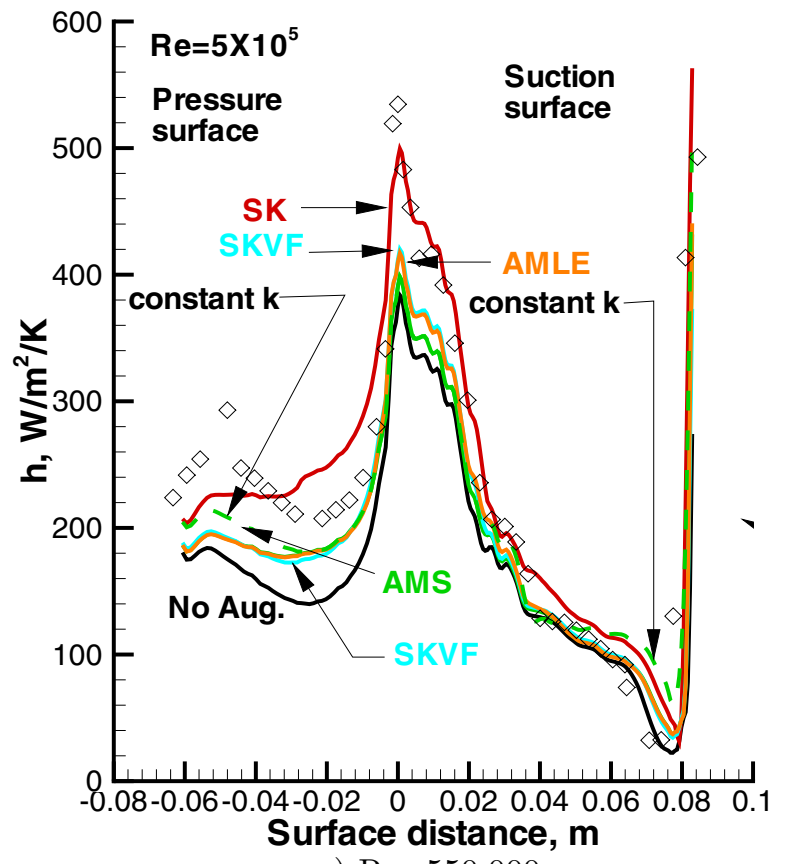

a) $\mathrm{Re}=550,000$

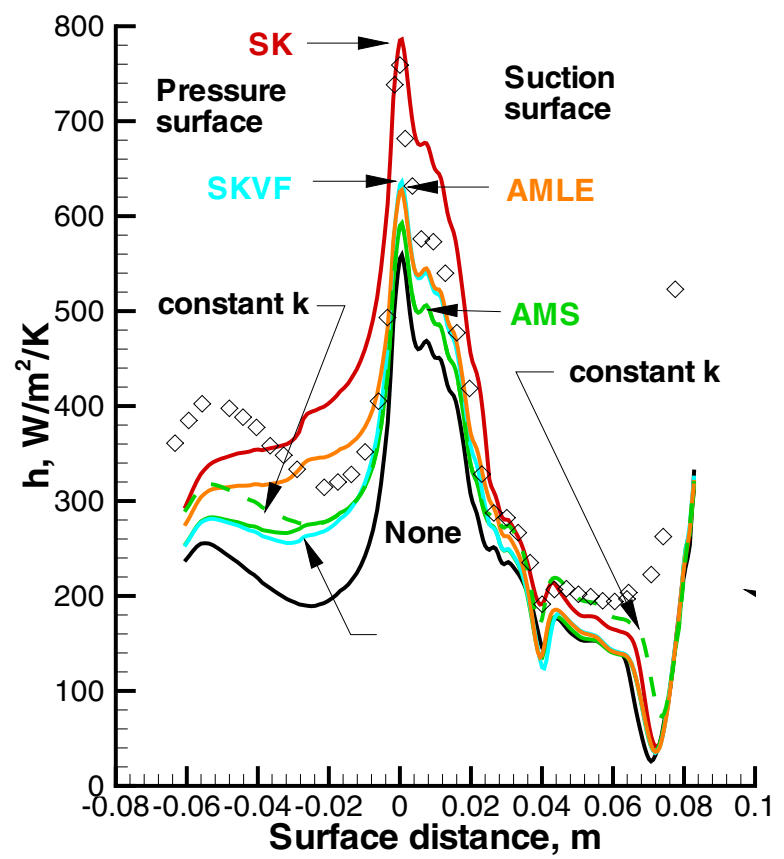

b) $\operatorname{Re}=1,090,000$

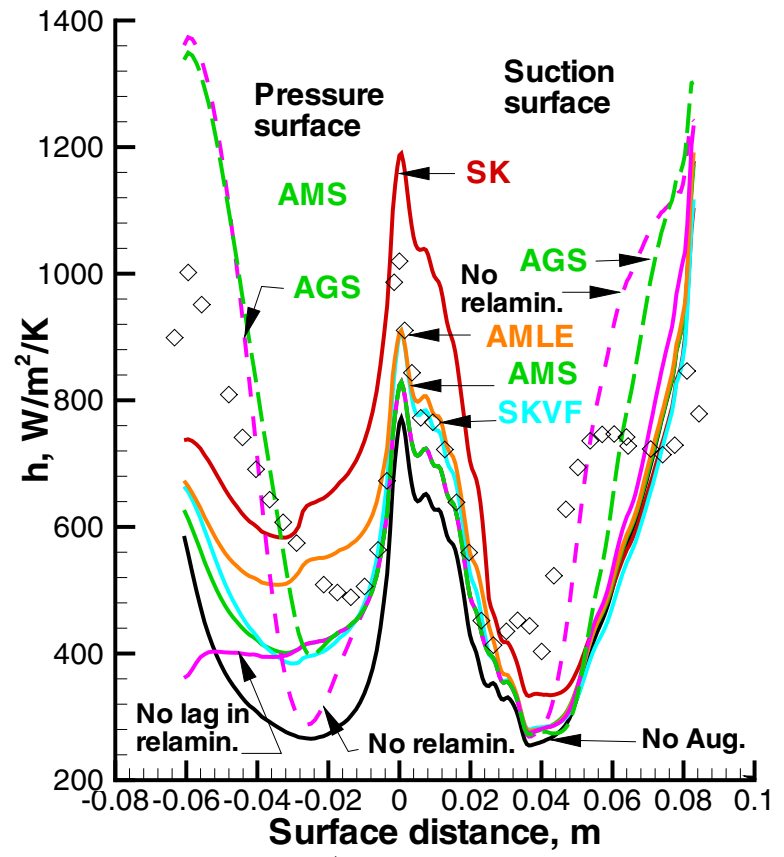

c) $\operatorname{Re}=2,110,000 M_{2}=1.1$

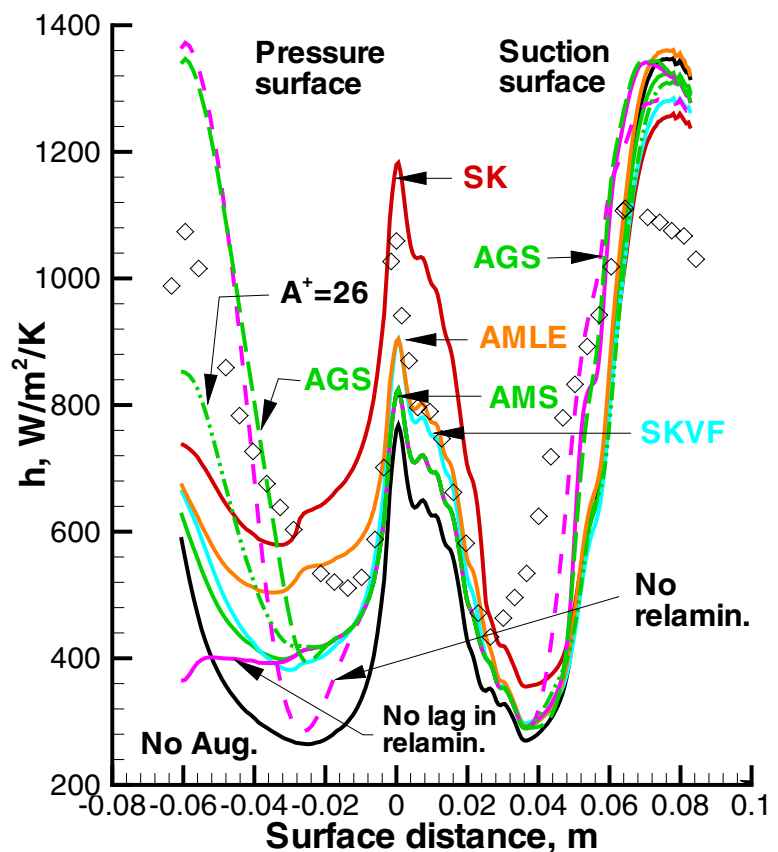

d) $\mathrm{Re}=2,110,000, M_{2}=0.92$

Fig. 6 Comparisons with data of Arts et al.[32]

average heat transfer for the suction surface. However, when the goodness measure for a model is how well it predicts the local heat transfer, the spike in heat transfer in some sense distorts the comparison. A comparison based on a square root of the sum of the squares of the difference between predicted and measured heat transfer will be large due to a few large differences in a small fraction of the surface distance.

For this geometry the AMLE model gives the best agreement with data. When using the SWGM transition model, assuming $k$ is constant is slightly preferable to using the SD model. This is because the suction surface transition is abrupt, and only slightly influenced by the local $T u$. 
Radomsky and Thole [31]. Comparisons for the fourth vane geometry are given in figure 5. Comparisons are shown for a single Reynolds number at inlet turbulence intensities of 10 and $20 \%$. This geometry has a large leading edge diameter-to-chord ratio. Consequently, the $L / D$ for the scale of turbulence is relatively small. On the pressure surface the AMLE, AMS, and SKVF models accurately predict the surface heat transfer for $T u=10 \%$, but over predict the heat transfer at $T u=20 \%$. The minimum experimental heat transfer is nearly the same at both turbulence intensities. There is a more rapid rise in the pressure surface heat transfer at $T u=20 \%$, suggestive of transition. However, no pressure surface transition was predicted.

In the leading edge region the AMLE model predicted the heat transfer best at $T u=10 \%$. However, it over predicted the heat transfer in this region at the higher turbulence intensity. At $T u=20 \%$ the AMS model agreed best with the data in the leading edge region. Results using the SKVF model were between those for the AMS and AMLE models.

On the suction surface transition is accurately predicted using the the SD model at $T u=10 \%$. Although not shown, the constant $k$ prediction also accurately predicted transition. At $T u=20 \%$ the measured heat transfer lies between predictions using these assumptions. inlet $T u$ of $10 \%$ prior to transition. After transition the predicted heat transfer agree reasonably well with the data, even though the downward slope in the predictions is greater than that seen in the data. The AGS model had a much longer transition length than is seen in the data.

Overall, the agreement for these cases is reasonably good. There is a small preference for using the AMS model, since it does not overpredict the leading edge region data at $T u=20 \%$.

Arts et al.[32]. Results for the last vane geometry to be compared are shown in figure 6 . In contrast to the other vane test cases this is a transonic vane. Comparisons are made at three Reynolds numbers and an exit Mach number of 1.1. A fourth comparison is shown at an exit Mach number of 0.92. Data were given for three turbulence intensities, and the comparisons are shown for the highest value of $6 \%$.

The comparisons for the pressure surface away from the leading edge will be discussed first. At the two lower Reynolds numbers the pressure surface heat transfer is not well predicted. The data indicate transition, but none of the models predict it. There is a slight improvement using the constant $k$ assumption for the variation in $T u$. Prior to the start of transition all augmentation models except the SK model are in reasonably good agreement with the data. The increase over the no augmentation model results is significant. At the highest Reynolds number of $2.1 \times 10^{6}$ the analysis shows the same trends as the data, but the predicted transition start location is too late. The AGS transition length model, or assuming $A^{+}=26$ in conjunction with the SWGM transition length model both result in reasonably accurate heat transfer predictions. The high Reynolds number data also illustrate issues associated with relaminarization. The assumption of no relaminarization initially gives very low heat transfer. This is because $A^{+}$is a function of $P^{+}$, and this is a region with strong favorable pressure gradients. These data show that it is appropriate to lag $K$ when relaminarization is allowed. Assuming no lag in relaminarization results in laminar heat transfer for the entire pressure surface, and gives a heat transfer close to the trailing edge only $40 \%$ of the experimental data. The no augmentation prediction agrees well with data in reference 32 for a low $T u$ of $1 \%$.

These data are the first to show that in the leading edge region the SK model is the preferred model, especially at the lower Reynolds numbers. At the highest Reynolds number the SK model is higher than the data in the leading edge region, and overpredicts for the front portion of the suction surface. Considering the other augmentation models, the AMLE model provides the better agreement.

At the two lower Reynolds numbers the suction side heat transfer is mostly laminar. All predictions agree with the data at the data at the lowest Reynolds number, including predicting the very rapid heat transfer rise at the trailing edge. At the next higher Reynolds number the shock behavior near $s=0.04 m$ is well predicted. However, the data show transition beginning shortly afterwards, but it is not predicted. At the highest Reynolds number suction surface transition occurs earlier than predicted. Although no shown, the constant $k$ assumption gave essentially the same predictions as the SD model assumptions. The assumption of no relaminarization is an improvement at the transonic exit Mach number, but gives only a slight improvement at the the subsonic exit Mach number. Prior to transition the AMLE model agrees well with the suction surface data. No prediction shows the constant heat transfer seen towards the rear of the suction surface at $M_{2}=1.1$. This plateau is not seen for the subsonic exit Mach number.

For this transonic vane the SK model predictions agreed better with the data than the AMLE predictions. On the pressure surface, the constant $k$ assumption improved predictions at low Reynolds numbers.

\section{Rotors}

While there are similarities between vane and rotor heat transfer distributions, there are significant differences, even when comparing steady state cascade tests. For the 
same exit Mach number, rotors typically have much higher inlet velocities than do vanes. The leading edge diameterto-chord ratio is often lower for rotors. These factors can result in very high heat transfer in the rotor leading edge region. Most rotor test cases have an adverse pressure gradient on the pressure side close to the leading edge. This leads to the prediction of abrupt transition at almost all Reynolds numbers. However, at low and moderate Reynolds numbers the pressure surface heat transfer is mostly laminar like, since the adverse pressure gradient is almost immediately followed by a strong favorable pressure gradient. A challenge for any heat transfer prediction methodology is to predict pressure surface heat transfer in this rapidly changing pressure field.

Heat transfer comparisons are shown for four rotor geometries. Comparisons are shown for the highest inlet turbulence intensity for which data were available. Comparisons are shown at different Reynolds numbers, but for brevity, only at one inlet flow angle for each geometry. One of the four rotor test conditions is for incompressible flow conditions. Two others are for subsonic exit Mach numbers, and the fourth is for an exit Mach number of 1.1.

Data of Zhang and Han[22]. Figure 7 compares data at the lowest and highest Reynolds numbers. The inlet $T u$ was $14 \%$ and $17 \%$ respectively. Due to an adverse pressure gradient, pressure surface transition was predicted to occur very close to the leading edge. Abrupt transition to fully turbulent flow was predicted. Following transition the AMS and AMLE model predictions are identical. At both Reynolds numbers transition was immediately followed by predicted relaminarization. The inlet $T u$ is high. Even so, the pressure side experimental heat transfer distributions are flat, which is consistent with laminar flow. The constant $k$ assumption for the variation in $T u$ gives excellent agreement for the lower Reynolds number case and good agreement in terms of the shape of the pressure surface heat transfer distribution at the higher Reynolds number.

Pressure surface comparisons at both Reynolds numbers show that the relaminarized prediction without augmentation is about a third of the experimental data. Although not shown in figure 7 , this prediction agrees reasonably well with the experimental data at low $T u$. Figure 7 shows that at both Reynolds numbers prediction without relaminarization have very low pressure surface heat transfer. The calculations were done assuming $A^{+}$to be a function of $P^{+}$using the Crawford and Kays[26] relationship. This relationship was developed to improve predictions for turbulent flows in the presence of favorable pressure gradients, and yields a higher value of $A^{+}$than that given by Cebeci and Smith[36]. It is most evident at the higher Reynolds number that this predicts a laminar-like boundary layer without any augmentation due to freestream

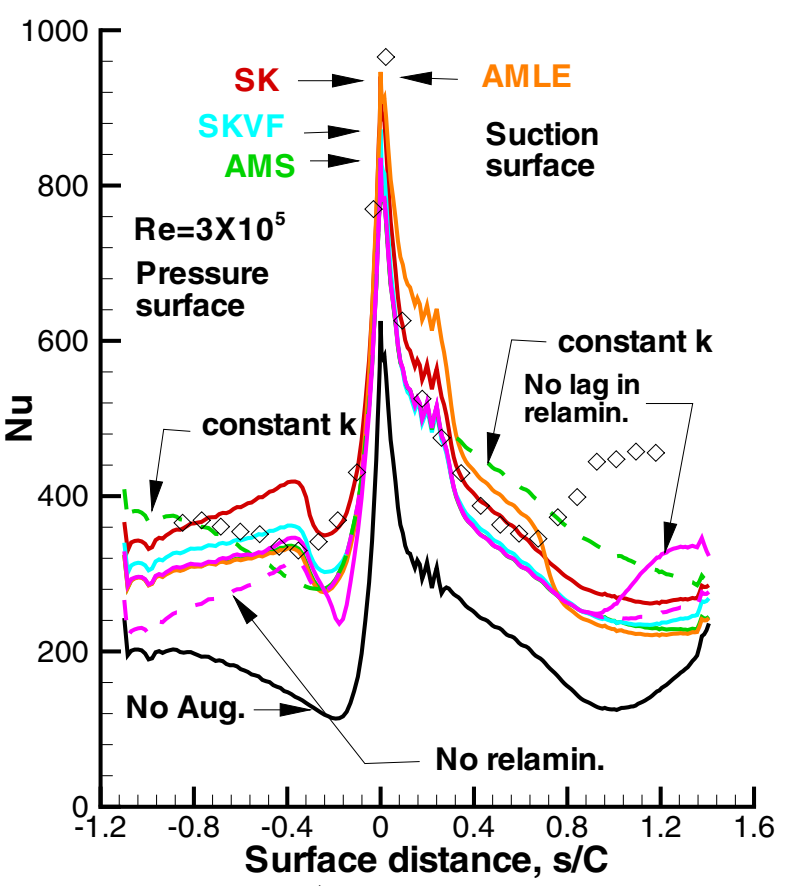

a) $R e=300,000$

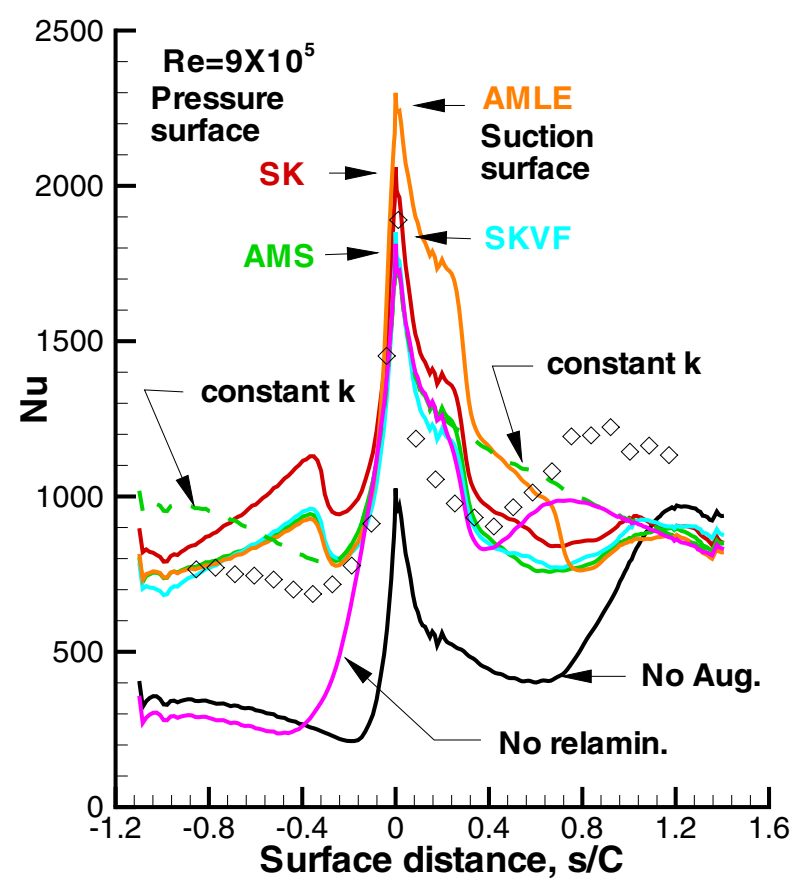

b) $R e=910,000$

Fig. 7 Comparisons with data of Zhang and Han[22].

turbulence. Explicit relaminarization is more appropriate for turbine heat transfer applications.

In the leading edge region at both Reynolds numbers no augmentation underpredicts the measured heat transfer. At the lower Reynolds number the AMLE and SK models 
are close to the data at the stagnation point. While, at the higher Reynolds number the SKVF and AMS models are close to the stagnation point data. On the pressure side of the leading edge region the agreement with data is good. However, on the suction side of this region the high heat transfer zone is wider than the data, especially using the AMLE model.

On the suction surface transition is not accurately predicted at either Reynolds number. The start of transition was predicted to be at $0.67<s / C<0.84$ using the constant $k$ or SD models at the lower Reynolds number. However, very long transition lengths were predicted. This resulted in much lower heat transfer than was measured.

For this rotor geometry augmentation along with relaminarization showed a significant improvement for pressure surface heat transfer. The constant $k$ assumption was better than the SD assumption. In the leading edge region the SKVF model was reasonably accurate, and the AMLE model produced too wide of a heat transfer distribution. The suction surface heat transfer was underpredicted after the start of transition.

Data of Giel et al.[33]. Figure 8 compares predictions with data for two Reynolds numbers. The inlet $T u$ was 13\%. For both Reynolds numbers the analysis predicted an abrupt pressure surface transition followed by relaminarization using a value for $K_{\text {CRIT }}$ of $3 \times 10^{-6}$. After transition, but before relaminarization, the analysis assumed no augmentation due to freestream turbulence. With no lag in relaminarization this region is relatively wide, and prior to relaminarization the heat transfer is not well predicted. At seen in some previous comparisons, the constant $k$ assumption along with relaminarization overpredicts the measured heat transfer. However, here the SD model assumption gives even higher heat transfer. In this region the analysis underpredicted pressure side heat transfer. The SKVF augmentation model agrees best with the data for the rear portion of the pressure surface at either Reynolds number. As expected, no augmentation underpredicted the pressure side heat transfer. Figure $8 \mathrm{a}$ shows that the SK model excessively overpredicts pressure side and leading edge heat transfer. The same behavior was seen at the higher Reynolds number.

In the leading edge region the AMLE model agreed best with the low Reynolds number stagnation region heat transfer, but exceeded the data at the higher Reynolds number. Because of the broader heat transfer distribution on the suction side of the leading edge the SKVF model is the preferred model.

On the suction surface the predicted heat transfer varies significantly with the modeling assumption used, with SKVF model showing the best results. At $s / C=1.2$ the predictions show heat transfer consistent with separa-

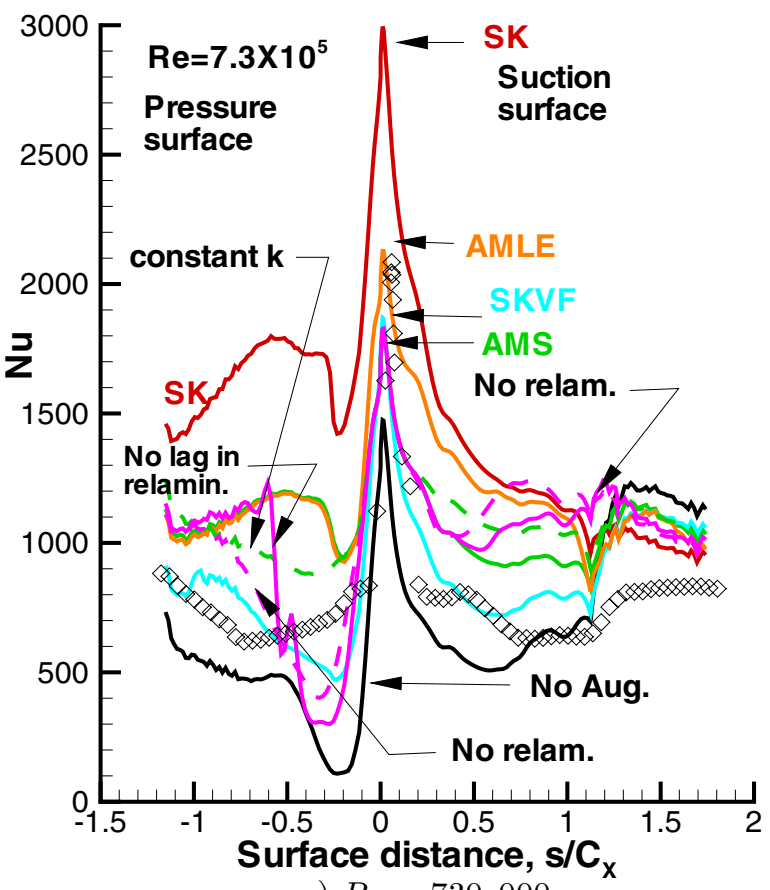

a) $R e=730,000$

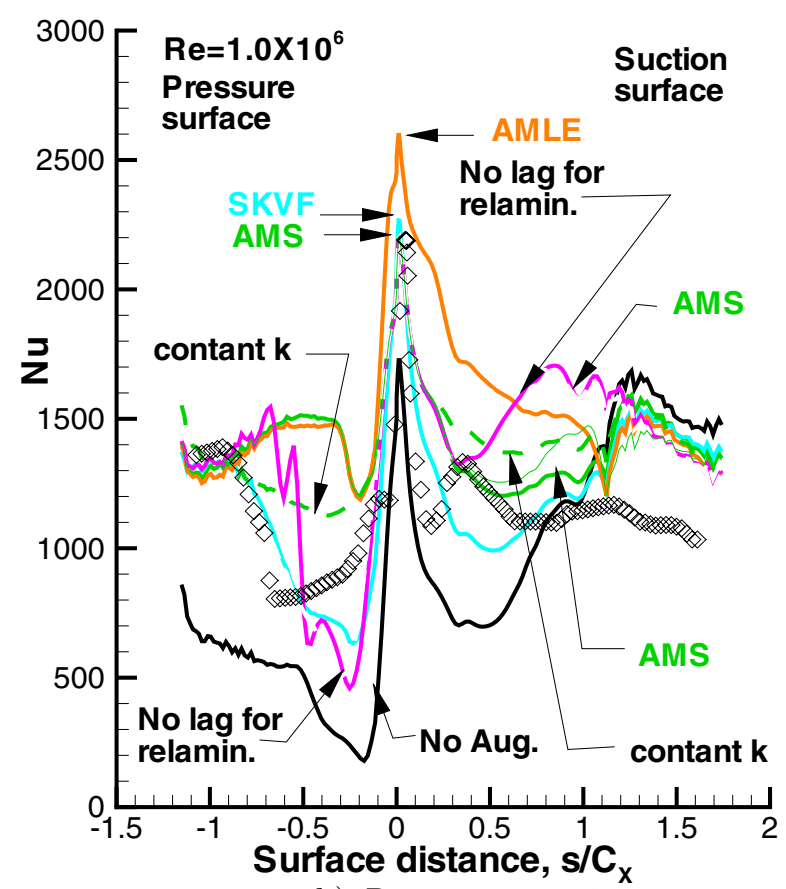

b) $R e=1,030,000$

Fig. 8 Comparisons with data of Giel et al.[33]

tion and rapid reattachment. This is not shock induced, and is not seen in the data. After this location all calculations overpredict the heat transfer. Assuming no relaminarization, or not lagging the relaminarization gave poorer agreement with the data. The data at the higher Reynolds 


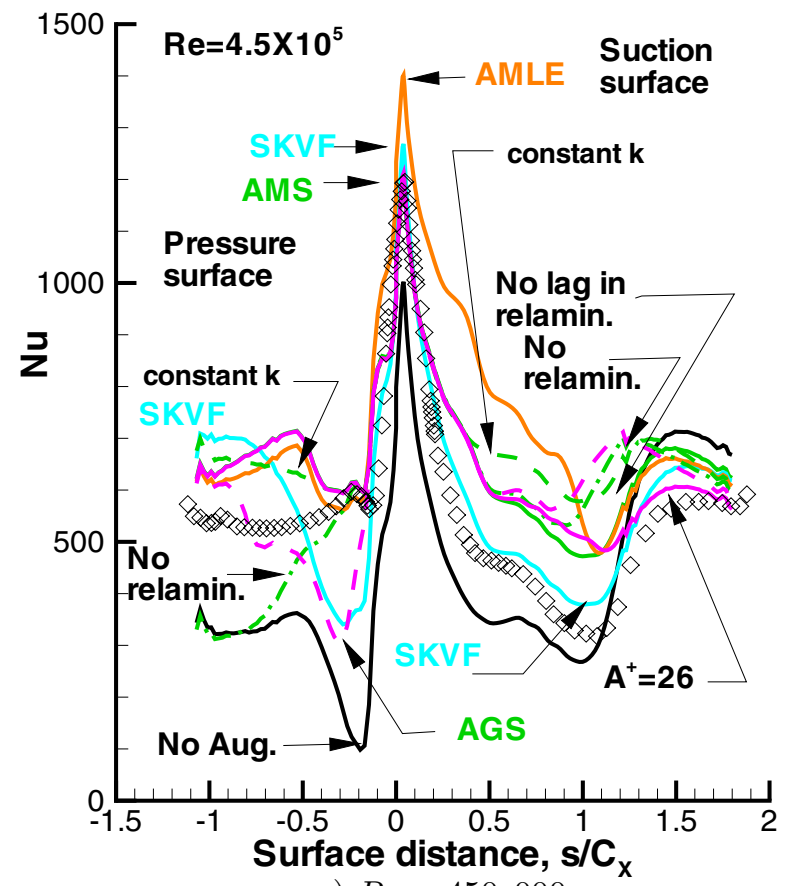

a) $R e=450,000$

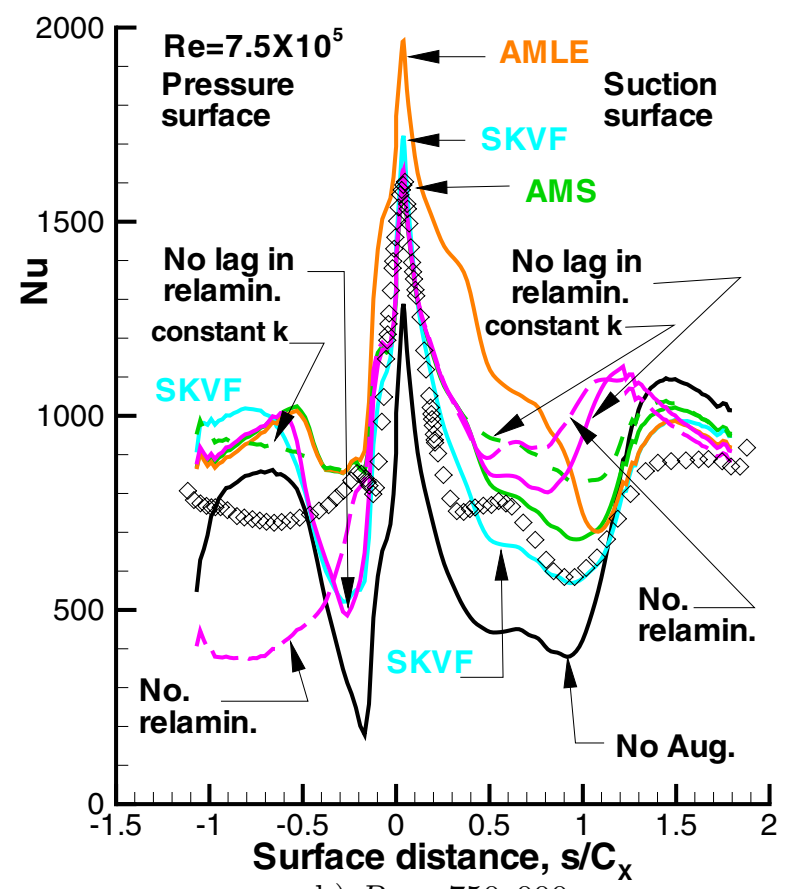

b) $R e=750,000$

number indicate relaminarization is appropriate. Close to the leading edge the heat transfer indicates transition, but the subsequent rapid heat transfer decrease shows a return to laminar-like heat transfer.

Overall, for this geometry the SKVF augmentation model agreed best with the data. The AMS model also

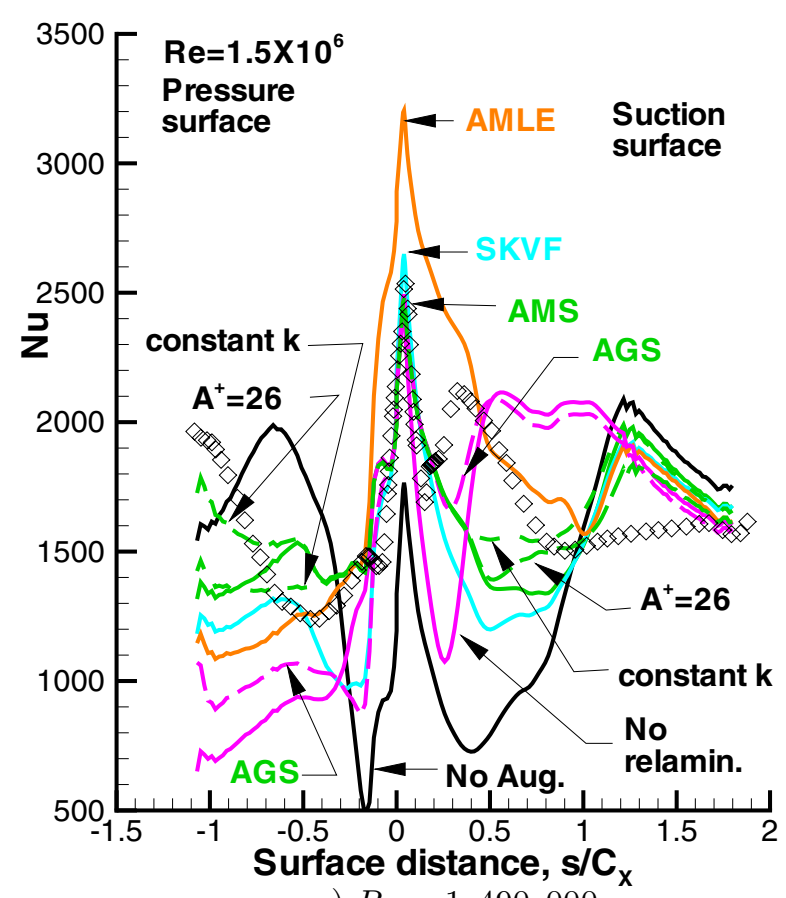

c) $R e=1,490,000$

Fig. 9 Comparisons with data of Giel et al.[34]

gave reasonably accurate predictions for the suction surface. On the suction surface predictions were sensitive to the whether or not $K$ was calculated using a lag equation.

Data of Giel et al.[34]. Figure 9 shows comparisons for three Reynolds numbers between 0.45 and $1.49 \times 10^{6}$. Predictions and data show that, for the two lower Reynolds numbers, the pressure surface relaminarized. After relaminarization the AMS and AMLE model predictions are the same. The SK model model results are not shown because they gave very high leading edge region heat transfer rates. There is also a significant difference in predicted heat transfer depending on which model is used for augmentation. Figure 2 shows that the SKVF model has greater augmentation than the AMS model in the near wall region, but lower augmentation away from the surface. Consequently, the SKVF prediction gave much lower heat transfer close to the leading edge. Due to the large values of $A^{+}$in the favorable pressure gradient of the pressure surface at the two lower Reynolds numbers, the no relaminarization prediction gives very low heat transfer rates. At the highest Reynolds number the pressure surface data show heat transfer consistent with turbulent flow. The best agreement was achieved when $A^{+}$was set to 26 . A calculation using the Cebeci-Smith variation of $A^{+}$with $P^{+}$was similar to the one assuming $A^{+}=26$.

In the leading edge region both the AMS and SKVF models are in good agreement with data for the peak heat transfer at all Reynolds numbers. On the suction side of the leading edge region the AMS model has a wider heat 


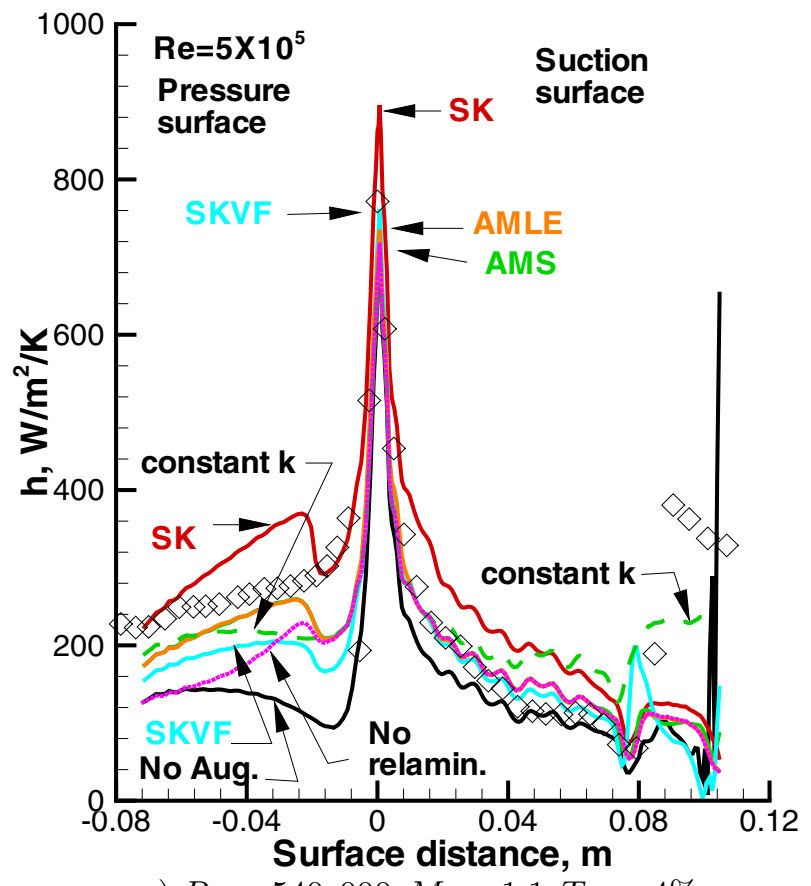

a) $R e=540,000, M_{2}=1.1, T u=4 \%$

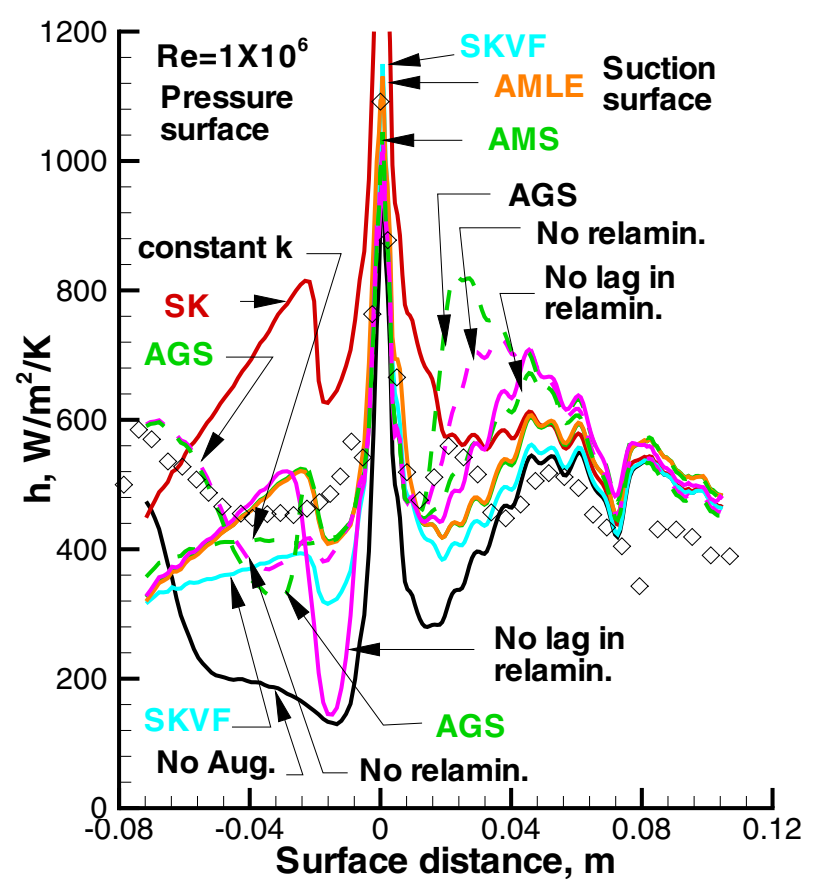

b) $R e=1,050,000, M_{2}=1.1, T u=6 \%$

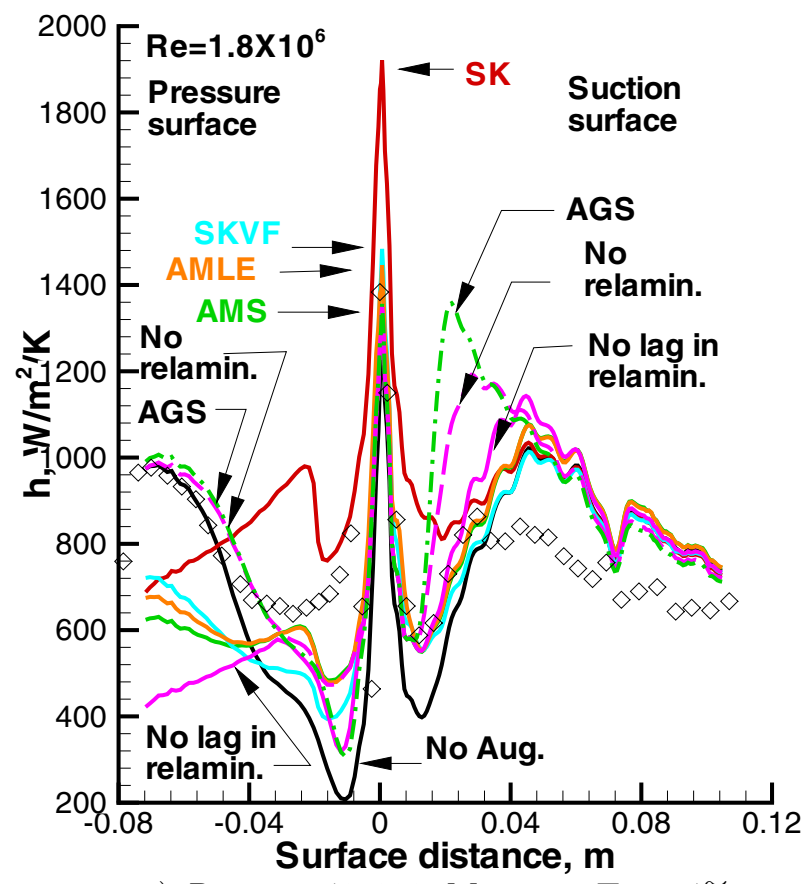

c) $R e=1,840,000, M_{2}=1.1, T u=4 \%$

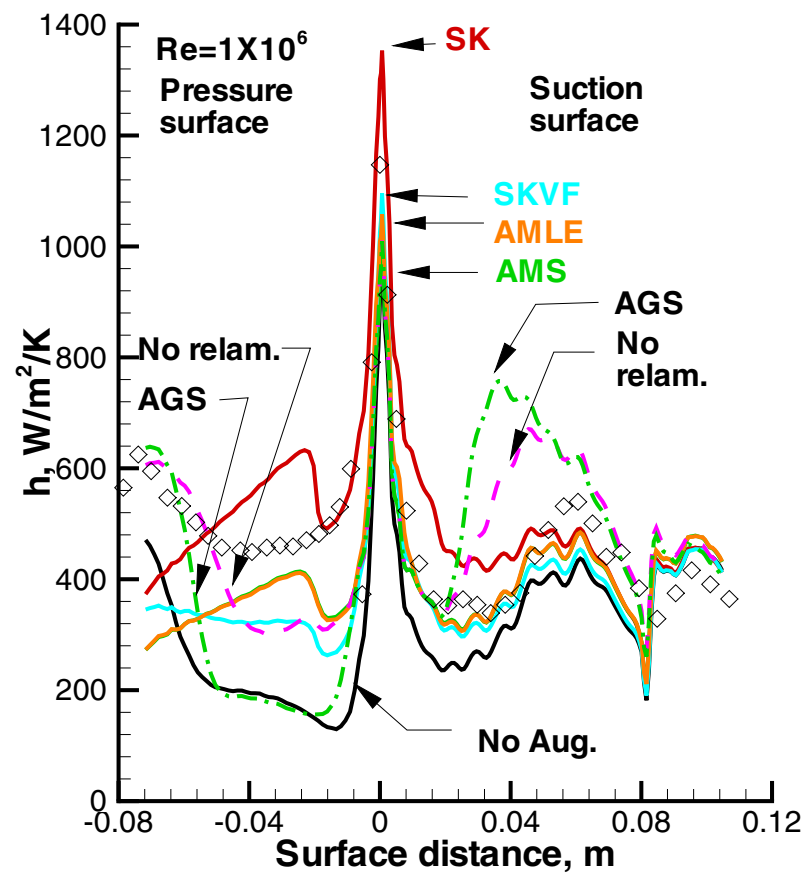

d) $R e=1,050,000, M_{2}=1.3, T u=4 \%$

Fig. 10 Comparisons with data of Arts et al.[35]

transfer distribution than the SKVF model. The AMLE model distribution is wider than the AMS distribution.

On the suction surface the SKVF model agrees well with the data at the two lower Reynolds numbers. The constant $k$ assumption shows poorer agreement with data than does the SD model for the variation in Tu. At the highest Reynolds number the data show similar behavior to that seen in figure $8 \mathrm{~b}$. Close to the leading edge there is transition followed by a rapid decrease in heat transfer, consistent with relaminarization. Both the AGS model and no relaminarization assumption show the transitional behavior. However, the predicted heat transfer remains 


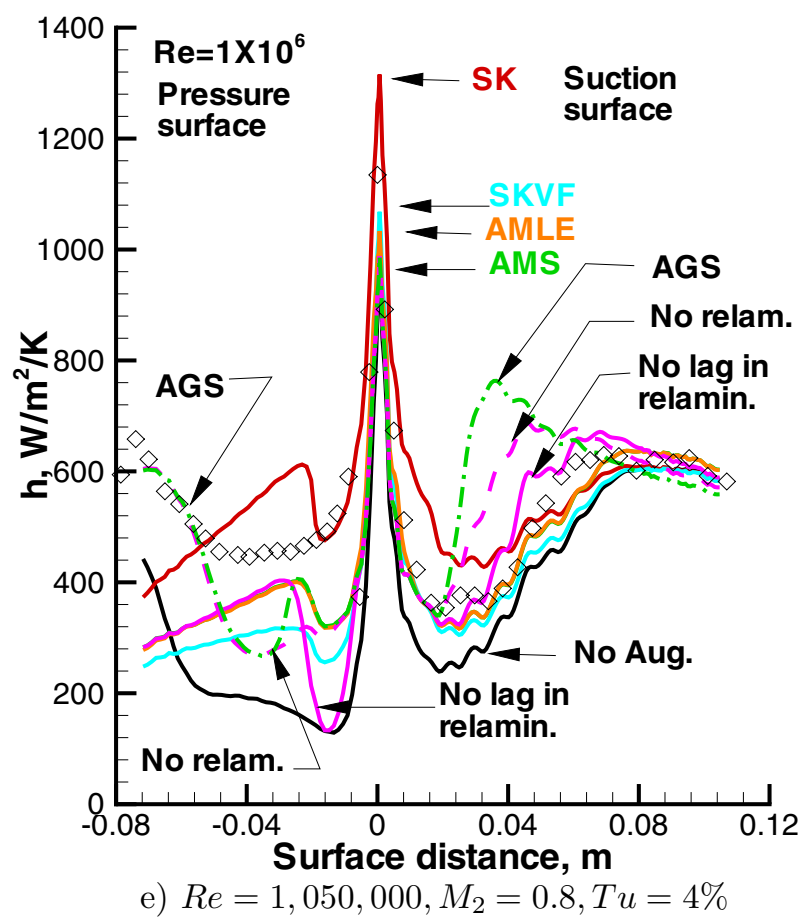

Fig. 10 Concluded

high, while the data decreases.

Data of Arts et al.[35]. Figure 10 shows comparisons for the rotor of Arts et al. [35]. Only one case had an inlet $T u$ of $6 \%$. For the remaining cases the inlet $T u$ was only $4 \%$. Even though the inlet $T u$ was fairly low, the models predict a significant heat transfer increase due to turbulence. At all Reynolds numbers, no augmentation underpredicts the pressure surface data. The SK model results overpredict the heat transfer prior to transition. At the lowest Reynolds number the AMS and AMLE results agree best with the data. The SKVF results are somewhat lower. Here, the constant $k$ assumption does not improve agreement with data. The three cases at the intermediate Reynolds number have similar behavior. The data show transition over the latter half of the pressure surface, and this is only predicted using the AGS transition model or assuming no relaminarization. Figure $8 \mathrm{~d}$ shows that for $M_{2}=1.3$, the AGS model heat transfer remains low for a large fraction of the pressure surface. When no relaminarization is assumed, the heat transfer is well predicted for the rear half of the pressure surface. However, the heat transfer is underpredicted for the forward half of the pressure surface. For the highest Reynolds number the effect of assumptions regarding relaminarization are clearly seen on the rear half of the pressure surface. No lag in relaminarization yields very low heat transfer. No relaminarization yields very good agreement. Predictions using the lagged model are midway between these two predictions.
Table III. Overall heat transfer differences, $\%$

\begin{tabular}{|c|c|c|c|c|}
\hline \multirow[t]{2}{*}{ Model } & \multicolumn{2}{|c|}{ Pressure surface } & \multicolumn{2}{|c|}{ Suction surface } \\
\hline & Avg. & Diff & Avg. & Diff \\
\hline & \multicolumn{4}{|c|}{ Vanes } \\
\hline NO-SD-RL-S-AV & $-32.4 \pm 16$ & 39 & $-31.3 \pm 16$ & 32 \\
\hline SK-SD-RL-S-AV & $28.2 \pm 18$ & 39 & $2.0 \pm 17$ & 28 \\
\hline AM-SD-RL-S-AV & $-6.6 \pm 12$ & 21 & $-17.9 \pm 15$ & 25 \\
\hline VF-SD-RL-S-AV & $-9.8 \pm 15$ & 23 & $-19.4 \pm 15$ & 25 \\
\hline AL-SD-RL-S-AV & $-2.1 \pm 14$ & 21 & $-9.1 \pm 19$ & 25 \\
\hline AM-CK-RL-S-AV & $-3.3 \pm 12$ & 18 & $-10.7 \pm 12$ & 19 \\
\hline AM-SD-RY-S-AV & $-11.8 \pm 17$ & 25 & $-12.6 \pm 14$ & 24 \\
\hline AM-SD-NR-S-AV & $-9.1 \pm 17$ & 25 & $-16.6 \pm 17$ & 24 \\
\hline AM-SD-RL-A-AV & $-3.4 \pm 12$ & 20 & $-23.1 \pm 15$ & 28 \\
\hline \multirow[t]{2}{*}{ AM-SD-RL-S-AC } & $-4.1 \pm 14$ & 22 & $-22.1 \pm 14$ & 24 \\
\hline & \multicolumn{4}{|c|}{ Rotors } \\
\hline NO-SD-RL-S-AV & $-19.2 \pm 15$ & 37 & $-23.2 \pm 16$ & 32 \\
\hline SK-SD-RL-S-AV & $40.1 \pm 26$ & 52 & $42.5 \pm 32$ & 43 \\
\hline AM-SD-RL-S-AV & $2.6 \pm 18$ & 22 & $6.9 \pm 15$ & 22 \\
\hline VF-SD-RL-S-AV & $4.4 \pm 20$ & 27 & $1.4 \pm 13$ & 20 \\
\hline AL-SD-RL-S-AV & $6.4 \pm 18$ & 26 & $26.3 \pm 27$ & 33 \\
\hline AM-CK-RL-S-AV & $2.3 \pm 19$ & 23 & $16.5 \pm 19$ & 25 \\
\hline AM-SD-RY-S-AV & $-2.8 \pm 23$ & 30 & $13.2 \pm 17$ & 24 \\
\hline AM-SD-NR-S-AV & $-7.8 \pm 8$ & 22 & $15.2 \pm 21$ & 28 \\
\hline AM-SD-RL-A-AV & $-0.9 \pm 18$ & 21 & $18.6 \pm 18$ & 30 \\
\hline AM-SD-RL-S-AC & $7.5 \pm 15$ & 23 & $7.4 \pm 15$ & 22 \\
\hline
\end{tabular}

In the leading edge region both the AMLE and SKVF models agrees best with the data at all Reynolds numbers. Here, the AMLE model does not show a wide heat transfer distribution on the suction side of the leading edge region.

On the suction surface there is good agreement with data at the lowest Reynolds number prior to the throat. As expected, the SK augmentation model overpredicts the heat transfer. The constant $k$ model for $T u$ variation also overpredicts the heat transfer as a result of predicting an earlier transition start. The constant $k$ model predicts a heat transfer rise after the throat, but still less than is seen in the data. Figure 10b shows that, at the middle Reynolds number and $T u=6 \%$, the AGS model predicts the initial rise in heat transfer. However, for the remainder of the suction surface this model's prediction is much higher than the data. Figures 10c-10e show that this model predicts a heat transfer rise due to transition prior to when it is seen in the data. Figures 10b, d, and e show that the analysis accurately predicted the heat transfer for the rear of the suction surface at $M_{2}=0.8$ and $M_{2}=1.3$. However, at the intermediate Mach number the predictions were not as accurate. Figure 10c shows that at the highest Reynolds number, the analysis overpredicted suction surface heat transfer over nearly half the surface distance.

\section{CONCLUDING REMARKS}

This work has shown the importance of including a model for the effects of freestream turbulence on laminar 
heat transfer. Table III summarizes the differences between predicted and measured heat transfer for all cases for both the pressure and suction surfaces. Even though the vanes and rotors are compared separately there is a similarity in the results. The no augmentation model underpredicts the pressure surface heat transfer by approximately forty percent for both the vanes and rotors. This model underpredicts the suction surface by approximately twenty percent. The SK model overpredicts the pressure surface heat transfer by up to forty percent. When the other model assumptions are held constant, the differences among the augmentation models are only eight percent for the vanes, and fifteen percent for the rotors. The AMLE model had the smallest underprediction for the vanes. Had it been restricted to just the leading edge region before becoming the AMS model, the overprediction of 12 percent for the rotor suction surface would have been reduced to nearly zero.

The heat transfer is underpredicted using the AMS, AMLE, or SKVF models with the SD variation of $T u$. When the SD assumption was replaced by the constant $k$ assumption, there was nearly a six percent increase in heat transfer. This indicates that the constant $k$ assumption would yield a more conservative and accurate prediction.

Neither the assumption that there was no relaminarization (NR), nor assuming that the relaminarization was not lagged (RY) improved the accuracy of the predictions. The AGS(A) transition length model was better than the SWGM(S) model only for the vane pressure surfaces. There was no improvement for the vane suction surface, nor for the rotor surfaces.

Generally, a constant value for $A^{+}(\mathrm{AC})$ showed improved agreement with data. Calculations using the Cebeci-Smith[36] variation of $A^{+}$with $P^{+}$were close to those for $A^{+}=26$. Because of relaminarization, the effects of varying $A^{+}$were muted in the five baseline models.

The deviation in average heat transfer follows the \pm sign. For the preferred models it was generally less than fifteen percent. While it is desired that this value be lower, it is inevitable that there is some variation in the accuracy of the experiments.

The values in the column labeled "Diff" are the average for the deviations for individual cases. A low value for "Diff" indicates that on average the model predicted the heat transfer accurately everywhere on the surface, in addition to accurately predicting the average heat for the surface. Unfortunately, the "Diff" values generally exceed $20 \%$. The high value of $28 \%$ for "Diff" shown for the the vane suction surface using the SK model indicates that while this model accurately predicts the average vane suction surface, the local heat transfer is not well predicted. Since "Diff" values are determined from the square of the difference between the predicted values and individual data
Table IV. Sensitivity of predicted heat transfer to turbulence

\begin{tabular}{|r|c|c|c|c|}
\hline Heat transfer & \multicolumn{2}{|c|}{ Stators } & \multicolumn{2}{c|}{ Rotors } \\
\cline { 2 - 5 } difference & $\begin{array}{c}\text { Pressure } \\
\text { side }\end{array}$ & $\begin{array}{c}\text { Suction } \\
\text { side }\end{array}$ & $\begin{array}{c}\text { Pressure } \\
\text { side }\end{array}$ & $\begin{array}{c}\text { Suction } \\
\text { side }\end{array}$ \\
\hline SK - No Aug. & 5.5 & 2.2 & 9.6 & 4.6 \\
AMS - No Aug. & 2.1 & 0.7 & 4.1 & 1.8 \\
SKVF - No Aug. & 2.0 & 0.7 & 2.9 & 1.3 \\
AMLE - No Aug. & 2.8 & 1.2 & 4.5 & 2.7 \\
\hline
\end{tabular}

points, positional uncertainties in regions of high heat transfer gradients contribute to the magnitude of this quantity.

Table IV summarizes the effects of different augmentation models by showing the sensitivity of each model to turbulence intensity. The values in the table are the percent increase in heat heat transfer due to a one percent increase in turbulence. The values are calculated from the percentage increase in heat transfer using each model over the no augmentation calculation. This quantity is divided by the inlet $T u$. These values are only due to augmentation, since the same value of $T u$ was used to calculate transition for models with and without augmentation. For an inlet $T u$ of $10 \%$, the AMS model gave a rotor pressure side augmentation of $41 \%$. The augmentation models are linear in $T u$ and are approximately proportional to $L^{-1 / 3}$. Therefore, at a turbulence intensity of $10 \%$, an increase in $T u$ of 1 percentage point, or a decrease in $L$ of $30 \%$ is expected to result in a $4 \%$ increase in heat transfer.

\section{REFERENCES}

1. Blair, M. F., 1983, "Influence of Free-Stream Turbulence on Turbulent Boundary Layer Heat Transfer and Mean Profile Development," ASME Journal of Heat Transfer, Vol. 105, pp. 33-47.

2. Blair, M. F., 1994, "An Experimental Study of Heat Transfer in a Large-Scale Turbine Rotor Passage," ASME Journal of Turbomachinery, Vol. 116, pp. 1-13.

3. Krishnamoorthy, V., and Sukhatme, S. P., 1989, "The Effect of Free-Stream Turbulence on Gas Turbine Blade Heat Transfer," ASME Journal of Turbomachinery, Vol. 111, pp. 497-501. 4. Galassi, L., King, P. I., and Elrod, W. C., 1990, "Effects of Inlet Turbulence Scale on Blade Surface Heat Transfer in a Linear Cascade," AIAA 90-2264, presented at the 26th Joint Propulsion Conference, Orlando, Florida, July 16-18, 1990.

5. Mehendale, A. B., Han, J. C., and Ou, S., 1991, "Influence of High Mainstream Turbulence on Leading Edge Heat Transfer," ASME Journal of Heat Transfer, Vol. 113, pp. 843-850.

6. Svensdotter, S., and Fransson, T., 1998, "Hot Film and Liquid Crystal Transition Measurements in a Cascade at Varying Re and Tu," AIAA 98-3453, presented at the 34th Joint Propulsion Conference, Cleveland, Ohio, July 13-15, 1998. 
7. Ames, F.E., Chao, W., and Barbot, P.A., 2003, "Measurement and Prediction of the Influence of Catalytic and Dry Low NOx Combustor Turbulence on Vane Surface Heat Transfer," ASME Journal of Turbomachinery, Vol. 125, pp. 221-231.

8. Kays, W.M., 1987, "STAN7, A Finite Difference Boundary Layer Code"

9. Boyle, R.J, and Simon, F.F., 1999, "Mach Number Effects on Turbine Blade Transition Length Prediction," ASME Journal of Turbomachinery, Vol. 121, pp. 694-702. 10. Vicedo, J., Vilmin, S., Dawes, W.N., and Savill, A.M., 2003, "Intermittency Transport Modeling of Separated Flow Transition," ASME paper GT-2003-38719.

11. Suzen, Y.B., Xiong, G., and Huang, P.G., 2002, "Predictions of Transitional Flows in Low-Pressure Turbines Using Intermittency Transport Equations," AIAA Journal, Vol. 40, No. 2, pp. 254-266.

12. Steelant, J., and Dick, E., 1996, "Modeling of Bypass Transition with Conditioned Navier-Stokes Equations Coupled to an Intermittency Transport Equation," Int. Journal for Numerical Methods in Fluids, Vol. 3, pp. 193220.

13. Smith, M.C., and Kuethe, A.M., 1966, "Effects of Turbulence on Laminar Skin Friction and Heat Transfer," Phys Fluids, Vol. 9, No. 12, Dec. 1966, pp. 2337-2344.

14. Van Fossen, G.J., Simoneau, R.J., and Ching, C.Y., 1994, "Influence of Turbulence Parameters, Reynolds Number, and Body Shape on Stagnation Region Heat Transfer," NASA TP 3487.

15. Dullenkopf, K., and Mayle, R.E., 1995, "An Account of Free-Stream Turbulence Length Scale on Laminar Heat Transfer," ASME Journal of Turbomachinery, Vol. 117, pp. 401-406.

16. Boyle, R.J., Giel, P.W., and Bunker, R.S., 2003, "Predictions for the Effects of Turbulence on Turbine Blade Heat Transfer," ISABE Paper 1178.

17. Ames, Forrest E, 1994, "Experimental Study of Vane Heat Transfer and Aerodynamics at Elevated Levels of Turbulence," NASA CR 4633.

18. Mayle, R.E., 1991, "The Role of Laminar-Turbulent Transition in Gas Turbine Engines," ASME Journal of Turbomachinery, Vol. 113, pp. 509-537.

19. White, F.M., 1974, "Viscous Fluid Flow," McGrawHill, Inc, New York.

20. Steelant, J. and Dick, E., 1999 "Prediction of By-Pass Transition By Means of a Turbulence Weighting Factor Part I: Theory and Validation," ASME Paper 99-GT-29. 21. Boyle, R.J., Lucci, B.L., Senyitko, R.G., 2002, "Aerodynamic Performance and Turbulence Measurements in a Turbine Vane Cascade," ASME Paper GT-2002-30434. 22. Zhang,L., and Han, J.-C., 1994, "Influence of Mainstream Turbulence on Heat Transfer Coefficients From a Gas Turbine Blade," ASME Journal of Heat Transfer, Vol. 116, pp. 896-903.
23. Jonas, P., Mazur, O., and Uruba, V., 1999, "Experiments on By-pass Boundary Layer Transition with Several Turbulence Length Scales," Third European Conference on Turbomachinery: Fluid Dynamics and Thermodynamics, pp 179-188, IMechE Conference Transaction, Professional Engineering Publishing, London.

24. Solomon, W.J., Walker, G.J., and Gostelow, J.P., 1995, "Transition Length Predictions Fir Flows With Rapidly Changing Pressure Gradients," ASME Journal of Turbomachinery, Vol. 118, pp. 744-753.

25. Abu-Ghannam, B.J., and Shaw, R., 1980, "Natural Transition of Boundary Layers-The Effects of Turbulence, Pressure Gradients and Flow History," Journal of Mech. Engr. Science, Vol. 22, pp. 213-228.

26. Crawford, M.E., and Kays, W.M., 1976, "STAN5 - A Program for Numerical Computation of Two-Dimensional Boundary Layer Flows, NASA CR-2742.

27. Chima, R.V., Giel, P.W., Boyle, R.J., 1993, "An Algebraic Turbulence Model for Three-Dimensional Viscous Flows," AIAA Paper 93-0083, (NASA TM-105931).

28. Ameri, A.A., and Arnone, A., 1992, "Navier-Stokes Turbine Heat Transfer Predictions Using Two-Equation Turbulence Closures," AIAA Paper 92-3067.

29. Chima, R.V., 1987 "Explicit Multigrid Algorithm for Quasi-Three- Dimensional Flows in Turbomachinery," AIAA Journal of Propulsion and Power, Vol. 3, No. 5, pp. 397-405.

30. Ames, F.E., Argenziano, M., and Wang, C., 2003, "Measurement and Prediction of Heat Transfer Distributions on an Aft Loaded Vane Subjected to the Influence of Catalytic and Dry Low NOx Combustor Turbulence," ASME paper GT-2003-38509.

31. Radomsky, R. and Thole, K.A., 2000, "Highly Turbulent Flowfield Measurements Around a Stator Vane," ASME Journal of Turbomachinery, Vol. 122, pp. 255-262. 32. Arts, T., Lambert de Rouvroit, M., and Rutherford, A.W., 1990, "Aero-Thermal Investigation of a Highly Loaded Transonic Linear Turbine Guide Vane Cascade," VKI Technical Note 174.

33. Giel, P. W., Bunker, R. S., Van Fossen, G. J., and Boyle, R. J., 2000, "Heat Transfer Measurements and Predictions on a Power Generation Gas Turbine Blade," ASME Paper 2000-GT-0209.

34. Giel, P. W., Boyle, R. J., and Bunker, R. S., 2003, "Measurements and Predictions of Heat Transfer on Rotor Blades in a Transonic Turbine Cascade," ASME paper GT2003-38839, to appear in the ASME Journal of Turbomachinery.

35. Arts. T., Duboue, J.-M., and Rollin, G., 1998, "Aerothermal Performance Measurements and Analysis of a Two-Dimensional High Turning Rotor Blade," ASME Journal of Turbomachinery, Vol. 120, pp. 494-499.

36. Cebeci, T., and Smith, A.M.O., 1974, Analysis of Turbulent Boundary Layers, Academic Press, N.Y. 
Public reporting burden for this collection of information is estimated to average 1 hour per response, including the time for reviewing instructions, searching existing data sources, gathering and maintaining the data needed, and completing and reviewing the collection of information. Send comments regarding this burden estimate or any other aspect of this collection of information, including suggestions for reducing this burden, to Washington Headquarters Services, Directorate for Information Operations and Reports, 1215 Jefferson Davis Highway, Suite 1204, Arlington, VA 22202-4302, and to the Office of Management and Budget, Paperwork Reduction Project (0704-0188), Washington, DC 20503.

1. AGENCY USE ONLY (Leave blank) 2. REPORT DATE 3. REPORT TYPE AND DATES COVERED

4. TITLE AND SUBTITLE

May 2004

Technical Memorandum

Predictions for the Effects of Free Stream Turbulence on Turbine Blade Heat Transfer

6. AUTHOR(S)

Robert J. Boyle, Paul W. Giel, and Forrest E. Ames

WBS-22-714-30-10

National Aeronautics and Space Administration

John H. Glenn Research Center at Lewis Field

Cleveland, Ohio 44135-3191

5. FUNDING NUMBERS

9. SPONSORING/MONITORING AGENCY NAME(S) AND ADDRESS(ES)

National Aeronautics and Space Administration

Washington, DC 20546-0001

8. PERFORMING ORGANIZATION REPORT NUMBER

E-14555

11. SUPPLEMENTARY NOTES

Prepared for the Turbo Expo 2004 sponsored by the American Society of Mechanical Engineers, Vienna, Austria, June 14-17, 2004. Robert J. Boyle, NASA Glenn Research Center; Paul W. Giel, QSS Group, Inc., 21000 Brookpark Road, Cleveland, Ohio 44135; and Forrest E. Ames, University of North Dakota, Main Campus, Grand Forks, North Dakota 58202. Responsible person, Robert J. Boyle, organization code 5820, 216-433-5889.

12a. DISTRIBUTION/AVAILABILITY STATEMENT

12b. DISTRIBUTION CODE

Unclassified - Unlimited

Subject Category: 34

Distribution: Nonstandard

Available electronically at http://gltrs.grc.nasa.gov

This publication is available from the NASA Center for AeroSpace Information, 301-621-0390.

13. ABSTRACT (Maximum 200 words)

An approach to predicting the effects of free stream turbulence on turbine vane and blade heat transfer is described. Four models for predicting the effects of free stream turbulence were in incorporated into a Navier-Stokes CFD analysis.

Predictions were compared with experimental data in order to identify an appropriate model for use across a wide range of flow conditions. The analyses were compared with data from five vane geometries and from four rotor geometries. Each of these nine geometries had data for different Reynolds numbers. Comparisons were made for twenty four cases. Steady state calculations were done because all experimental data were obtained in steady state tests. High turbulence levels often result in suction surface transition upstream of the throat, while at low to moderate Reynolds numbers the pressure surface remains laminar. A two-dimensional analysis was used because the flow is predominately two-dimensional in the regions where free stream turbulence significantly augments surface heat transfer. Because the evaluation of models for predicting turbulence effects can be affected by other factors, the paper discusses modeling for transition, relaminarization, and near wall damping. Quantitative comparisons are given between the predictions and data.

14. SUBJECT TERMS 15. NUMBER OF PAGES

Turbine; Heat transfer; Turbulence 22

\begin{tabular}{|c|c|c|}
\hline $\begin{array}{c}\text { 17. SECURITY CLASSIFICATION } \\
\text { OF REPORT } \\
\text { Unclassified }\end{array}$ & $\begin{array}{c}\text { 18. SECURITY CLASSIFICATION } \\
\text { OF THIS PAGE } \\
\text { Unclassified }\end{array}$ & $\begin{array}{c}\text { 19. SECURITY CLASSIFICATION } \\
\text { OF ABSTRACT } \\
\text { Unclassified }\end{array}$ \\
\hline
\end{tabular}

NSN 7540-01-280-5500

Standard Form 298 (Rev. 2-89)

Prescribed by ANSI Std. Z39-18 298-102 

